\title{
The Causal Role of Magnesium Deficiency in the Neuroinflammation, Pain Hypersensitivity and Memory/Emotional Deficits in Ovariectomized and Aged Female Mice
}

\author{
Jun Zhang $\mathbb{( D}^{1-3, *}$ \\ Chun-Lin Mai ${ }^{1, *}$ \\ Ying Xiong' \\ Zhen-Jia Lin' \\ Ying-Tao Jie \\ Jie-Zhen Mai' \\ Chong Liu' \\ Man-Xiu Xie ${ }^{4}$ \\ Xin Zhou (iD) ${ }^{2,3}$ \\ Xian-Guo Liu ${ }^{1,5,6}$
}

'Department of Physiology and Pain Research Center, Zhongshan School of Medicine, Sun Yat-sen University,

Guangzhou, 510080, People's Republic of China; ${ }^{2}$ Department of Anesthesiology,

Guangdong Provincial People's Hospital,

Guangdong Academy of Medical Sciences,

Guangzhou, 510080, People's Republic of

China; ${ }^{3}$ Guangdong Cardiovascular Institute, Guangzhou, 510080, People's Republic of China; ${ }^{4}$ Department of Anesthesiology, Sun Yat-sen University Cancer Center, State Key Laboratory of Oncology in South China, Collaborative Innovation Center for Cancer Medicine, Guangzhou, 510060, People's Republic of China; ${ }^{5}$ Department of Anesthesiology, Guangdong Second Provincial Central Hospital, Guangzhou, 510317, People's Republic of China; ${ }^{6}$ Guangdong Province Key Laboratory of Brain Function and Disease, Guangzhou, 510080, People's Republic of China

*These authors contributed equally to this work

Correspondence: Xian-Guo Liu; Xin

Zhou

Email liuxg@mail.sysu.edu.cn;

zhoux89@mail2.sysu.edu.cn
Purpose: Postmenopausal women often suffer from chronic pain, memory decline and mood depression. The mechanisms underlying the neuronal disorders are not fully understood, and effective treatment is still lacking.

Methods: Oral administration of magnesium-L-threonate was tested to treat the neuronal disorders in ovariectomized and aged female mice. The pain hypersensitivity, memory function and depression-like behaviors were measured with a set of behavioral tests. Western blots, immunochemistry and in situ hybridization were used to assess molecular changes.

Results: Chronic oral administration of magnesium-L-threonate substantially prevented or reversed the chronic pain and memory/emotional deficits in both ovariectomized and aged female mice. We found that phospho-p65, an active form of nuclear factor-kappaB, tumor necrosis factoralpha and interleukin-1 beta were significantly upregulated in the neurons of dorsal root ganglion, spinal dorsal horn and hippocampus in ovariectomized and aged mice. The microglia and astrocytes were activated in spinal dorsal horn and hippocampus. Calcitonin gene-related peptide, a marker for peptidergic C-fibers, was upregulated in dorsal horn, which is associated with potentiation of C-fiber-mediated synaptic transmission in the model mice. In parallel with neuroinflammation and synaptic potentiation, free $\mathrm{Mg}^{2+}$ levels in plasma, cerebrospinal fluid and in dorsal root ganglion neurons were significantly reduced. Oral magnesium-L-threonate normalized the neuroinflammation, synaptic potentiation and $\mathrm{Mg}^{2+}$ deficiency, but did not affect the estrogen decline in ovariectomized and aged mice. Furthermore, in cultured dorsal root ganglion neurons, estrogen at physiological concentration elevated intracellular $\mathrm{Mg}^{2+}$, and downregulated phospho-p65, tumor necrosis factor-alpha and interleukin-1 beta exclusively in the presence of extracellular $\mathrm{Mg}^{2+}$.

Conclusion: Estrogen decline in menopause may cause neuroinflammation by reducing intracellular $\mathrm{Mg}^{2+}$ in neurons, leading to chronic pain, memory/emotional deficits. Supplement $\mathrm{Mg}^{2+}$ by oral magnesium-L-threonate may be a novel approach for treating menopause-related neuronal disorders.

Keywords: magnesium-L-threonate, postmenopause, neuroinflammation, chronic pain, memory, depression

\section{Introduction}

Many postmenopausal women suffer from chronic pain, ${ }^{1,2}$ memory decline ${ }^{3}$ and mood depression. ${ }^{4}$ The mechanisms underlying the comorbidity of the somatosensory and cognitive/emotional deficits are largely unknown. 
Previous works have shown that neuroinflammation, characterized by the upregulation of proinflammatory cytokines, such as TNF- $\alpha$, IL- $1 \beta$, and glial activation, contributes to chronic neuropathic pain and memory/ emotional impairments induced by peripheral nerve injury $^{5-9}$ and anti-cancer agents. ${ }^{10-12}$ Similarly, the inflammation resulting from estrogen decline in postmenopausal women has been proposed to cause cognitive disorders. ${ }^{13,14}$ The data suggested that neuroinflammation might be also a common cause for chronic pain and cognitive/emotional deficits in menopause conditions. However, how the estrogen decline leads to neuroinflammation remains elusive.

It has been shown that serum $\mathrm{Mg}^{2+}$ is decreased in postmenopausal women ${ }^{15,16}$ and in ovariectomized rats. ${ }^{17}$ Interestingly, experimental $\mathrm{Mg}^{2+}$ deficiency in the rat induces an inflammatory syndrome characterized by leukocyte and macrophage activation, and release of inflammatory cytokines. ${ }^{18} \mathrm{Mg}^{2+}$ deficiency also results in anxiety and depression in animals and humans. ${ }^{19}$ Likewise, our recent works show that $\mathrm{Mg}^{2+}$ deficiency may contribute to the chronic pain ${ }^{10}$ and memory/emotional deficits ${ }^{11,12}$ by activation of TNF- $\alpha / \mathrm{NF}-\kappa \mathrm{B}$ pathway in the rats treated with antineoplastic agents, including vincristine and cyclophosphamide. Previous works including ours show that chronic oral administration of magnesium-L-threonate (L-TAMS, also called MgT), which is capable of elevating brain $\mathrm{Mg}^{2+}$, improves spatial learning in both naïve rats ${ }^{20}$ and mice with Alzheimer's disease. ${ }^{21}$ Oral L-TAMS also prevents and restores the memory deficits induced by peripheral nerve injury, ${ }^{22}$ and attenuates the chronic pain ${ }^{10}$ and memory/emotional deficits ${ }^{11,12}$ induced by the antineoplastic agents. A clinical trial indicates that the global cognitive ability of older adults can be improved by oral L-TAMS. ${ }^{23}$ Together, these clinical and experimental data suggest that $\mathrm{Mg}^{2+}$ deficiency might play a key role in the neuroinflammation that induces the neuronal disorders. As $31 \%$ of $\mathrm{Mg}^{2+}$ in the body is distributed inside cells, where it functions as a coactivator for 600 enzymes, ${ }^{24}$ intracellular $\mathrm{Mg}^{2+}$ deficiency may trigger neuroinflammation. However, the causal link between intracellular $\mathrm{Mg}^{2+}$ level and neuroinflammation in estrogen decline is still not determined.

In the present work, we hypothesized that estrogen decline may cause neuroinflammation by reducing intracellular $\mathrm{Mg}^{2+}$ in neurons, leading to chronic pain, memory/emotional deficits. To test this, we asked the following questions: Could estrogen decline cause intracellular $\mathrm{Mg}^{2+}$ deficiency? Could intracellular $\mathrm{Mg}^{2+}$ deficiency directly induce neuroinflammation? Is chronic oral administration of L-TAMS capable of preventing and reversing the estrogen decline-induced neuroinflammation and chronic pain and memory/emotional deficits?

\section{Materials and Methods}

\section{Animals}

Adult (8-12-week-old) female C57BL/6 mice and aged (19-month-old in average) female C57BL/6 mice were purchased from the Institute for Experimental Animals of Sun Yat-sen University (Guangzhou, China). The mice were housed in a $12 \mathrm{~h}$ light/dark cycle (06:0018:00 h) and temperature $\left(24 \pm 1^{\circ} \mathrm{C}\right)$ controlled cage with $50-60 \%$ humidity. The mice had access to sterile water and standard laboratory chow ad libitum. All experimental protocols and animal handling procedures were approved by the Animal Care Committee of Sun Yat-sen University and in accordance with the guidelines of the National Institutes of Health on animal care and ethical guidelines. Animals were randomly assigned to each group.

\section{Ovariectomy (OVX)}

Ovariectomy is a model of menopause. ${ }^{25}$ OVX was performed by double dorsolateral incisions according to previous work. ${ }^{26}$ The mice were anesthetized with $2 \%$ isoflurane (RWD Life Science, China) with oxygen flow of $0.3-0.5 \mathrm{~L} / \mathrm{min}$. Dorsal incisions were made in the area between the last rib and hips, each ovary together with its capsule and part of the oviduct was removed. In shamoperated mice, the ovaries were identically exposed but not removed. To avoid infection, penicillin (100,000 units/ $\mathrm{kg}$, i.m.) was given after operation, and the mice were allowed to recover for 7 days.

\section{Treatment with Magnesium-L-Threonate (L-TAMS)}

According to previous studies, ${ }^{20,27}$ mice received L-TAMS (Neurocentria Inc., Walnut Creek, CA, USA) at a dose of $910 \mathrm{mg} / \mathrm{kg} / \mathrm{d}(75 \mathrm{mg} / \mathrm{kg} / \mathrm{d}$ elemental magnesium) daily in the drinking water $(6 \mathrm{~mL} / \mathrm{d} /$ mouse $)$. Oral application of L-TAMS was initiated 1 week after OVX in adult female mice and continued until the end of experiments. Aged mice received L-TAMS throughout the experiments (Figure 1). 

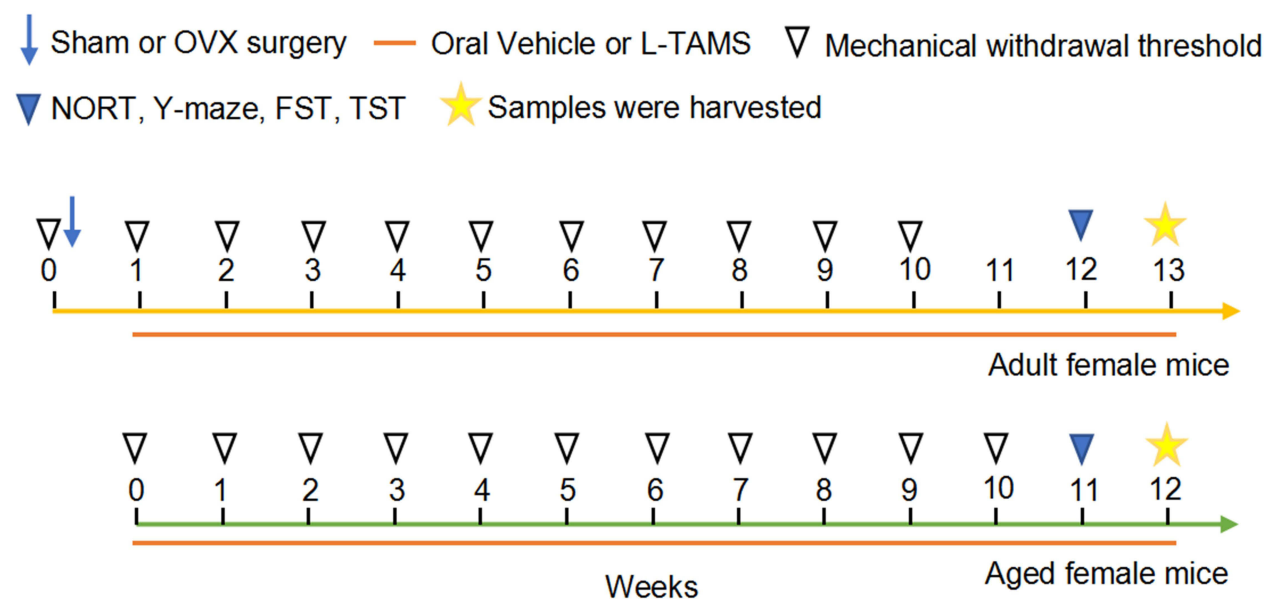

Figure I Experimental procedure. The yellow line represents adult female mice, and the green line represents aged female mice. The treatments are indicated with different symbols.

\section{Experimental Design}

The adult mice (8-12-week-old) were randomly divided into following four groups: sham mice treated with vehicle (Sham), sham mice treated with L-TAMS (Sham + L-TAMS), ovariectomized mice treated with vehicle (OVX), and ovariectomized mice treated with L-TAMS (OVX + L-TAMS). The aged female mice (19month-old in average) were divided into two groups: aged + vehicle and aged + L-TAMS, and adult mice $(8$ weeks) served as control. The experimental procedures are shown in Figure 1. Mechanical pain behaviors were assessed before and weekly after OVX. As a previous work showed that 12 weeks after OVX mice began to develop significant cognitive dysfunction, ${ }^{28}$ and our data showed that 10 weeks after OVX the mechanical allodynia reached maximal (Figure 2A, red squire). Thus, the memory function and depression-like behaviors were assessed 12 weeks after sham or OVX operation, that is, oral L-TAMS or vehicle for 11 weeks. The mice were euthanized after the behavioral tests and DRG, spinal cord and hippocampus were harvested for further analysis. The mice, with which spontaneous pain was measured with conditioned place preference or electrophysiological recording were performed, were not used for other behavioral tests and samples were not harvested.

\section{Behavioral Tests}

All behavioral tests were conducted from 9:00 a.m. to 5:00 p.m. The experimenter who conducted the behavioral tests was blinded to the treatments.

\section{Mechanical Withdrawal Threshold}

The mice were acclimated to the test environment for 3 days before experiments. Before each test, the mice were allowed to acclimate again for 30 minutes. Fifty percent paw withdrawal threshold (PWT) was assessed with the up-down method described previously. ${ }^{29}$ The procedure was the same as previous studies. ${ }^{6}$ Briefly, mice were placed on a wire grid and the plantar surface of the hind paw was stimulated with a set of Von Frey filaments (0.04-2 g for mice; North Coast medical), each stimulus lasted for 6-8 seconds. Quick withdrawal or licking of the paw in response to the mechanical stimulus was considered a positive response. Basal nociceptive sensitivity was tested before OVX and L-TAMS administration. The mice with basal PWT $\leq 0.16$ g were excluded. Mechanical withdrawal threshold was measured weekly in each group until the PWT stabilized.

\section{Conditioned Place Preference (CPP)}

CPP was used to determine the presence of spontaneous (ongoing) pain in animals. Relief of pain is a form of rewarding, and clonidine as an analgesic agent was not rewarding in the absence of pain but became rewarding when there is ongoing pain. ${ }^{30}$ To put it simply, mice were given intraperitoneal injections of $0.1 \mathrm{mg} / \mathrm{kg}$ clonidine or equivalent saline in paired boxes with different patterns and colors. After training three times in each box, the two boxes were connected and the mice were allowed free access for $15 \mathrm{~min}$ to either box. An infrared camera was used to record the trace of mice. The ratio of time that each mouse spent in clonidine paired box and saline paired box were recorded for statistical analysis. The mice were 

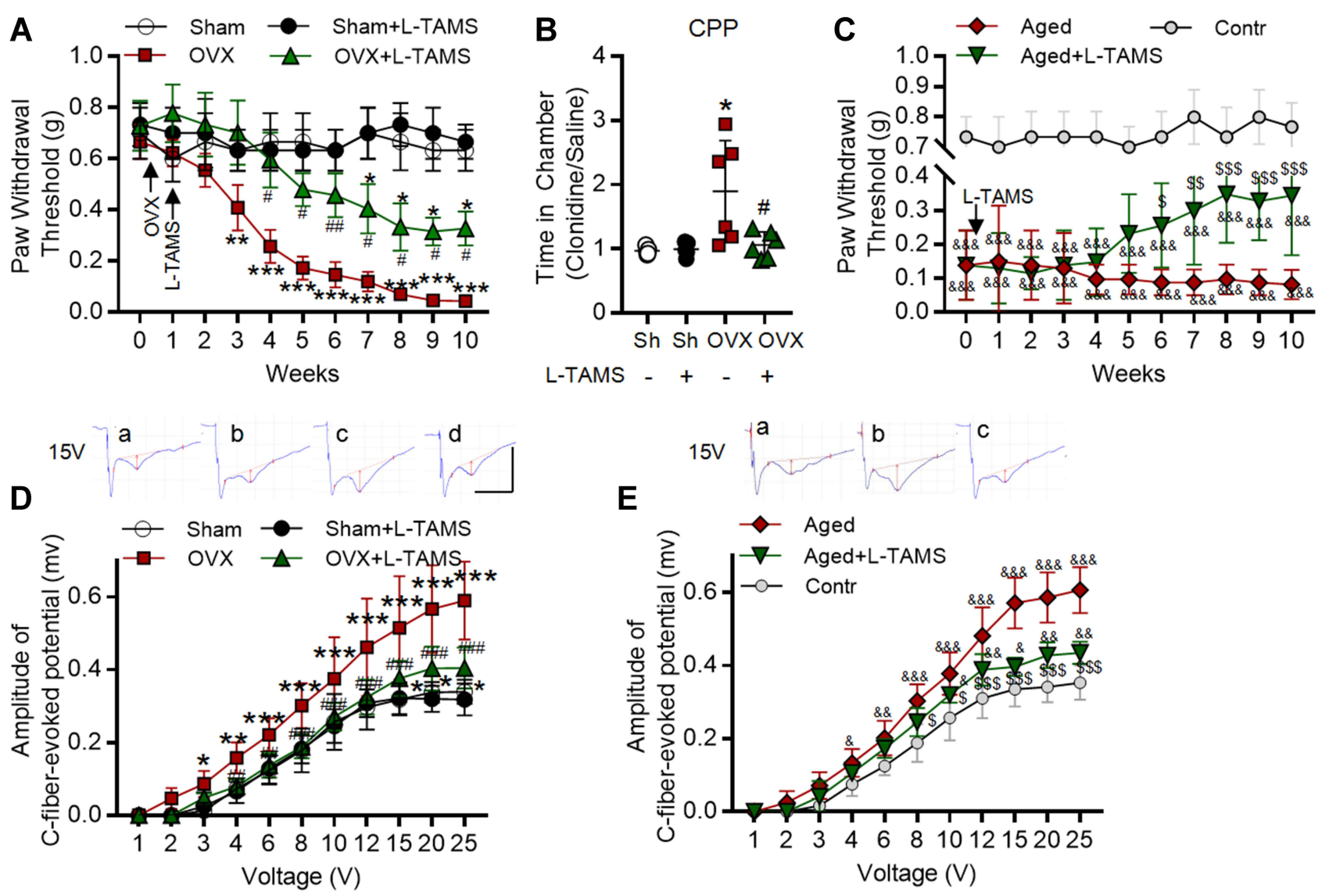

Figure 2 Oral application of L-TAMS attenuates the pain hypersensitivity and potentiation at C-fiber synapses in both ovariectomized and aged female mice. (A) The time courses of paw withdrawal thresholds elicited by von Frey filaments in Sham $(n=6)$, Sham + L-TAMS $(n=6)$, OVX $(n=9)$, and OVX + L-TAMS $(n=9)$ are shown. $(B)$ In the conditioned place preference (CPP) experiment, the ratio of time that mice spent in clonidine paired box and saline paired box were recorded. Treatment with L-TAMS significantly suppressed clonidine induced chamber preference in OVX group ( $\mathrm{n}=5$ in Sham and Sham + L-TAMS groups, $n=6$ in OVX and in OVX $+\mathrm{L}-\mathrm{TAMS}$ groups). (C) The time courses of paw withdrawal thresholds in control $(8$ weeks, $n=6)$, aged $(18$ months, $n=10)$ and aged + L-TAMS ( $n=10)$ mice are shown. (D) The stimulusresponse curves of $\mathrm{C}$-fiber evoked potentials in the spinal dorsal horn in different groups as indicated are shown ( $\mathrm{n}=6-8$ per group). Raw traces show the field potentials evoked by $15 \mathrm{~V}$ in Sham (a), Sham + L-TAMS (b), OVX (c), and OVX + L-TAMS (d) groups. The red vertical line represents the amplitude of the C-fiber evoked field potentials. (E) The stimulus-response curves of $C$-fiber evoked potentials in different groups as indicated are shown ( $n=6-8$ per group). Raw traces show the field potentials evoked by $15 \mathrm{~V}$ in Control (a), Aged (b) and Aged + L-TAMS (c) groups. The data in A, C, D, E were analyzed by two-way ANOVA with Tukey's test. The data in B

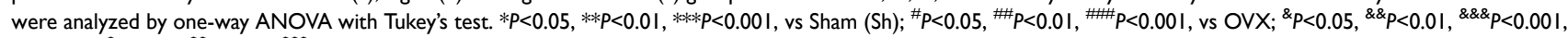
vs Contr; ${ }^{\$} P<0.05,{ }^{\$} P<0.01,{ }^{\$ \$} P<0.001$, vs Aged.

euthanized at the end of the CPP test and not used for subsequent sampling because they were intraperitoneally injected with analgesics.

\section{Novel Object Recognition Test (NORT)}

NORT was applied to assess short-term memory function as previously described. ${ }^{31}$ Briefly, mice were tested on a round field with a diameter of $50 \mathrm{~cm}$. In the first stage, each mouse was placed in the arena for 5 minutes, and two identical "old objects" were placed. Ten minutes later, a new different object replaced the less preferred old one, and each mouse was allowed to explore the two objects for 5 minutes. The recognition index was calculated as the ratio of time that the mice spent exploring the novel object over total exploration time.

\section{Y-Maze}

Spontaneous alternation that measures spatial working memory was assessed with a Y-maze apparatus, which is consisting of $\mathrm{a}, \mathrm{b}$ and $\mathrm{c}$ three Plexiglas wall-protected arms $(60 \mathrm{~cm}$ long $\times$ $10 \mathrm{~cm}$ wide $\times 20 \mathrm{~cm}$ high at $120^{\circ}$ ). Briefly, mice were allowed to explore all three arms of the maze freely, this behavior was driven by the innate curiosity of rodents to explore new areas. ${ }^{32}$ Eight-minute trials per animal were recorded by Ethovision 3.1 software (Noldus, Netherlands). Percentage of alternations (ie, abc, bca, and cba) normalized to total triplet arm entries were used as an index of spatial working memory.

\section{Forced Swimming Test (FST)}

The FST was applied to assess the depression state of animals. $^{33}$ Mice were forced to swim in a cylindrical 
barrel (25 $\mathrm{cm}$ in diameter and $45 \mathrm{~cm}$ high) containing 30 $\mathrm{cm}$ of water at $25 \pm 1^{\circ} \mathrm{C}$ for $6 \mathrm{~min}$. The immobility time in the last 4 min was recorded as an indicator of depressionlike behavior.

\section{Tail Suspension Test (TST)}

The TST shares a common behavioral measurement with the FST. ${ }^{34}$ The tails of mice were suspended using adhesive tape for $6 \mathrm{~min}$, and the time of immobility in the last 4 min is recorded.

\section{Electrophysiologic Recording}

Protocols of recording the C-fiber evoked field potential in the spinal dorsal horn have been described in our previous studies. ${ }^{5,35}$ Briefly, mice were anesthetized with urethane (Sigma, USA, $1.5 \mathrm{~g} / \mathrm{kg}$, i.p.). L4-L5 laminectomy was performed and the left sciatic nerve trunk was explored. The sciatic nerve was stimulated by test stimulus $(0.5 \mathrm{~ms}$ duration, at increasing voltages $1-25 \mathrm{~V}$ ) with a bipolar platinum hook electrode. C-fiber evoked field potentials were recorded in the superficial spinal dorsal horn (L4 and L5 segments) with a glass microelectrode (filled with 0.5 $\mathrm{M}$ sodium acetate, impedance 1-3M $\Omega$ ). The amplitudes of C-fiber evoked field potentials were recorded and analyzed with WinLTP program (http://www.winltp.com/), and the stimulus-response curve was drawn. The animals were euthanized at the end of the experiments.

\section{Culture of DRG Neurons}

Dorsal root ganglion (DRG) neurons were dissociated and cultured following our previous work. ${ }^{36}$ Briefly, mice were euthanized by $\mathrm{CO}_{2}$ and then decapitated immediately. DRG neurons were excised with sharp tweezers and freed from their capsule and connective tissue, this process was performed on ice. DRG neurons were cut up with sharp scissors and digested with $2 \mathrm{mg}$ trypsin (Sigma, USA) and $3 \mathrm{mg}$ collagenase (Sigma, USA) in $5 \mathrm{~mL}$ DMEM/F12 medium (GIBCO, USA) for about 25 minutes in $37^{\circ} \mathrm{C}$ water bath. To stop the digestion, $5 \mathrm{~mL}$ of complete medium $(10 \%$ fetal bovine serum, $1 \%$ penicillinstreptomycin solution, 1\% glutamine in DMEM/F12 medium, all from Gibco, Grand Island, NY) was added. After mechanical and enzymatic dissociation, DRG neurons were collected and seeded on a 24-well plate coated with poly-L-lysine (Sigma, USA) and then transferred to the humidified atmosphere $\left(5 \% \mathrm{CO} 2,37^{\circ} \mathrm{C}\right)$ for 4 hours. Then, the complete medium was changed to remove the nonadherent cells. In addition, a custom magnesium-free medium was used to test $\mathrm{Mg}^{2+}$ deficits in neuroinflammation. In this experiment, 17 $\beta$-estradiol was added to the medium on the second day and third day. The cultured DRG neurons were fixed by $4 \%$ paraformaldehyde for immunofluorescence on the fourth day.

\section{Western Blot}

After 12 weeks of oral administration of L-TAMS or vehicle, cardiac perfusion with $4^{\circ} \mathrm{C}$ PBS buffer was performed under anesthesia with urethane (Sigma, USA, 1.5g/ $\mathrm{kg}$, i.p.) of mice. Then, the hippocampus and spinal dorsal horn in each group were harvested and homogenized with protease inhibitor cocktail (Roche, USA) and phosphatase inhibitor (Roche, USA). Proteins in samples were separated on $12.5 \%$ PAGE gel (EpiZyme, China) and then transferred to PVDF membranes (Millipore, USA). Membranes were blocked in 5\% bovine serum albumin (BSA) solution for $60 \mathrm{~min}$ at room temperature and then incubated with primary antibodies: TNF- $\alpha$ (1:1000, rabbit; Bioworld Technology, Item No. BS1857, Inc., Louis Park, MN, USA), IL-1 $\beta$ (1:1000, rabbit; Abcam, Item No. ab9722, Cambridge, UK), phosphorylated NF-kB p65 (Ser311) (1:1000, rabbit; Affinity Biosciences, Item No. AF3389, OH, USA), NF-kB p65 (1:1000, rabbit; Cell Signaling Technology, Item No. D14E12, MA, USA), phosphorylated I $\mathrm{I} B \alpha$ (1:1000, rabbit; Cell Signaling Technology, Item No. 2859, MA, USA), ІкB $\alpha$ (1:1000, mouse; Cell Signaling Technology, Item No. L35A5, MA, USA), CGRP (1:5000, Rabbit; Abcam, Item No. ab37657, Cambridge, UK), $\beta$-actin (1:1000, mouse; Cell Signaling Technology, Item No. 3700, MA, USA) overnight at $4^{\circ} \mathrm{C}$. Horseradish peroxidase-conjugated IgG was applied for $1 \mathrm{~h}$. Chemiluminescent liquid (Millipore, USA) was used to detect the immune complex. Bands were quantified using a computer-assisted imaged analysis system (ImageJ; National Institutes of Health, Bethesda, MD, USA).

\section{Immunofluorescence}

Mice treated with L-TAMS or vehicle for 12 weeks were anesthetized with urethane (Sigma, $1.5 \mathrm{~g} / \mathrm{kg}$, i.p.), and then perfused intracardially with $4{ }^{\circ} \mathrm{C}$ PBS followed by $4 \%$ paraformaldehyde (PFA). L4-5 DRG, L3-L5 segments of spinal cord and hippocampus were harvested and post-fixed in the 4\% PFA solution for 4-6 hours, then transferred to $30 \%$ sucrose in PBS for 3 days at $4^{\circ} \mathrm{C}$. The tissues were sliced into $20 \mu \mathrm{m}$ sections using a cryotome (CM3050S, Leica, Wetzlar, Germany) 
and processed for immunohistochemical staining. The cultured DRG neurons were fixed with 4\% PFA for 20 min and then washed in PBS. The tissue sections and cultured DRG neurons were blocked for 60 and $30 \mathrm{~min}$ at room temperature, and then incubated overnight at $4^{\circ}$ C with TNF- $\alpha$ (1:200, Rabbit, Bioworld Technology, Item No. BS1857, Inc., MN, USA), IL-1 $\beta$ (1:200, goat, R\&D Systems, Item No. AF-401-NA, USA), phosphorylated NF- $\kappa$ B p65 (Ser311) (1:100; Affinity Biosciences, Item No. AF3389, OH, USA), CGRP (1:500, goat, Abcam, Item No. ab36001, Cambridge, UK), CGRP (1:500, mouse, Abcam, Item No. ab81887, Cambridge, UK), plant lectin B4 (1:200; Sigma, Item No. L2895, USA), NeuN (1:400, mouse; Millipore, Item No. MAB377, USA), GFAP (1:800, mouse, Cell Signaling Technology, Item No. 3670, MA, USA), and Iba1 (1:500, goat, Abcam, Item No. ab5076, Cambridge, UK) overnight at $4^{\circ} \mathrm{C}$. Then, the samples were incubated with secondary antibodies (Alexa Fluor ${ }^{\circledR} 488,555,647$; Life Technologies, CA, USA) for $1 \mathrm{~h}$ at room temperature and mounted on coverslips with Fluoromount-G with DAPI (Southern Biotech, Birmingham, AL, USA). Fluorescent images were obtained with EVOS FL microscope (Thermo Fisher Scientific, USA), and Nikon C2 confocal microscopes. All parameters such as exposure time and gain were fixed to ensure standardization between each sample. ImageJ software (National Institutes of Health, USA) was used to analyze the count of cells and fluorescence intensity. Fluorescent signal intensity was quantified using relative integrated density (IntDen), an appropriate threshold was set and kept constant in all groups. IntDen of sham or control group was set as the baseline, the data from other groups were normalized with the baseline.

\section{RNA Fluorescence in situ Hybridization (FISH)}

Fluorescently labeled locked nucleic acid-modified oligonucleotide probes complementary to mice Tnf and Il-1 $\beta$ were purchased from GenePharma (Suzhou, China). The probe sequences were as follows: Tnf 5'aag+ttcag +tagacagaagagcg ctggta+tgagatagcaaa+tcgggaggag+tagacaa+taaaggggttaggaa+ggcctgaga+tcttatc $3^{\prime}$. Il-1 $\beta$ 5'ttcagacac+ttgcacaa+ggaaggtccg+tcaacttca + aagaacagttgtctaa +tgggaacg+tcacacctaggt+tctgttc+tagagagtg $3^{\prime}$. NC $5^{\prime}$ tgctt +tgcacggtaacgcc+tgtttt3'. After deparaffinization and deproteinization, the slides were prehybridized with $1 \times$ hybridization buffer without probes. The hybridization was carried out overnight in a $1 \times$ hybridization buffer $(100 \mu \mathrm{L})$ with pre-denatured $2 \mu \mathrm{M}$ miRNA probes at $37^{\circ}$ C. After washing, the slides were mounted on coverslips with Fluoromount-G with DAPI (Southern Biotech, Birmingham, AL, USA). Fluorescent images were obtained with EVOS FL microscope (Thermo Fisher Scientific, USA) and Nikon C2 confocal microscopes.

\section{Measurement of Extracellular and Intracellular Free Magnesium}

The plasma and cerebrospinal fluid (CSF) of mice treated with L-TAMS or vehicle for 12 weeks were collected from the left ventricle and foramen magnum, respectively. For collection of CSF, the mice were anesthetized with urethane (Sigma, USA, $1.5 \mathrm{~g} / \mathrm{kg}$, i.p.), the posterior neck skin was cut, and the muscles were bluntly separated to expose the foramen magnum. A plastic hose was used to connect a glass tube with fine tip and a $2.5-\mathrm{mL}$ syringe. The cerebrospinal fluid was collected by inserting the tip of tube into the foramen magnum at depth of $1-2 \mathrm{~mm}$, and stored at $-80^{\circ} \mathrm{C}$. The concentrations of free $\mathrm{Mg}^{2+}$ in the plasma and CSF were measured with the calmagite chromometry method. ${ }^{37}$

The preparation method of DRG neuron suspension is the same as the above method of DRG neuron culture. The intracellular free $\mathrm{Mg}^{2+}$ in DRG neurons was determined by flow cytometry (FCM). ${ }^{10}$ In brief, DRG neurons were incubated with Magnesium Green (Invitrogen, Massachusetts, USA) in PBS for $30 \mathrm{~min}$ at $37^{\circ} \mathrm{C}$. Then, the DRG neurons were washed in PBS and fixed by $1 \%$ PFA. The data were collected by flow cytometry (CytoFLEX S, Beckman Coulter, USA). The mean fluorescence intensity of 30,000 neurons in each mouse was used to measure the intracellular free $\mathrm{Mg}^{2+}$ in the neurons. In cultured DRG neurons, the intracellular free $\mathrm{Mg}^{2+}$ was determined by a multifunctional microplate reader (Synergy HTX) using Magnesium Green (Invitrogen, Massachusetts, USA). The protocol of antibody incubation and fixation are the same as above.

\section{Plasma I7 $\beta$-Estradiol Measurement}

Mice treated with L-TAMS for 12 weeks were anesthetized with urethane, the blood was harvested from hearts, and the plasma was stored at $-80^{\circ} \mathrm{C}$ until use. Estrogen in mouse plasma was measured using commercially available Estradiol ELISA kits (Cayman, Item No. 501890) 
according to the manufacturer's instructions. This kit is a competitive assay that has a range of $0.61-10,000 \mathrm{ng} / \mathrm{L}$. Extraction of the sample with methanol before the measurement was made to increase the accuracy of the test. 50 $\mu \mathrm{L}$ of each plasma sample was used according to the manufacturer's specification.

\section{Statistical Analysis}

All data are presented as the mean \pm SD. GraphPad Prism 7.0 software (GraphPad Software, CA, USA) was used to calculate statistical significance. The results of mechanical pain behavior and electrophysiological data were analyzed with two-way ANOVA followed by Tukey's post hoc test. Other results were analyzed with one-way ANOVA followed by Tukey's post hoc test. $P<0.05$ was considered as significant difference.

\section{Results}

Chronic Oral Magnesium-L-Threonate Attenuates the Pain Hypersensitivity and Potentiation at C-Fiber Synapses in Both Ovariectomized and Aged Female Mice

We first tested if supplement $\mathrm{Mg}^{2+}$ by oral administration of L-TAMS was able to prevent the chronic pain induced by ovariectomy (OVX). As shown in Figure 2A, compared to sham mice (open circle), the paw withdrawal thresholds (PWT) elicited by mechanical stimuli decreased in OVX mice treated with either normal water and L-TAMS with time, while the change was significantly smaller in L-TAMS-treated mice (Figure 2A, triangle) than that in vehicle-treated mice (Figure 2A, square). L-TAMS did not affect PWT in sham mice (Figure 2A, filled circle). The results indicate that oral L-TAMS prevents the mechanical allodynia induced by OVX but has no effect on pain sensitivity in sham mice. We also tested if oral L-TAMS might also attenuate the spontaneous pain induced by OVX with CPP test, and found that OVX mice treated with L-TAMS spend less time in the chamber receiving clonidine than those treated with vehicle (Figure 2B). While no difference was detected between the two treatments in sham mice. The results are consistent with the clinical observation that estrogen decline leads to chronic pain in menopause women. ${ }^{1,38}$ To further investigate the treatment effect of L-TAMS on the chronic pain sensitivity induced by estrogen decline, we measured PWT in control (8-week-old) and aged (19-month-old in average) female mice. We found that PWTs were significantly lower in aged mice compared to control mice in vehicle-treated groups, indicating that aged mice also exhibit mechanical allodynia. In the aged mice, PWTs declined slightly with time in the vehicle group, but increased significantly in the L-TAMS-treated group, indicating that oral L-TAMS may reverse the mechanical allodynia in the aged mice (Figure 2C).

To confirm the results and investigate the underlying mechanisms, we recorded the C-fiber evoked field potentials in spinal dorsal horn following the behavioral tests and calculated the stimulus-response curves. As shown in Figure $2 \mathrm{D}$ and $\mathrm{E}$, the curves were shifted rightwards in both OVX and aged mice treated with vehicle, and changes were significantly smaller in the OVX and aged mice treated with L-TAMS. L-TAMS had no effect on sham and control mice. The data suggest that synaptic transmission in C-fiber synapses is potentiated in OVX and aged mice, and the potentiation is depressed by oral L-TAMS.

\section{Oral Magnesium-L-Threonate Attenuates the Memory/Emotional Deficits in Both Ovariectomized Mice and Aged Female Mice}

In consistence with the clinical data showing memory deficits in menopause women, ${ }^{39}$ we found that the memory function was impaired in OVX and aged mice, as in vehicle-treated groups, recognition index assessed by NORT and alternation index assessed by Y-maze in both OVX mice and aged mice were significantly lower than those in sham mice and control mice, respectively (Figure 3A and B). Interestingly, we found that both indexes were significantly higher in OVX and aged mice treated with L-TAMS than those treated with vehicle (Figure 3A and B), while no difference was detected in sham mice between vehicle- and L-TAMS-treated groups. Thus, the memory function in OVX and aged mice but not in sham and control mice was substantially improved by oral L-TAMS. We found that in OVX and aged female mice treated with vehicle, the immobility time assessed by both FST and TST was significantly higher compared to sham and control mice, and the change was substantially reduced in L-TAMS-treated groups (Figure 3C and D). The results indicate that oral L-TAMS also attenuates the depression-like behaviors in OVX and aged mice. 

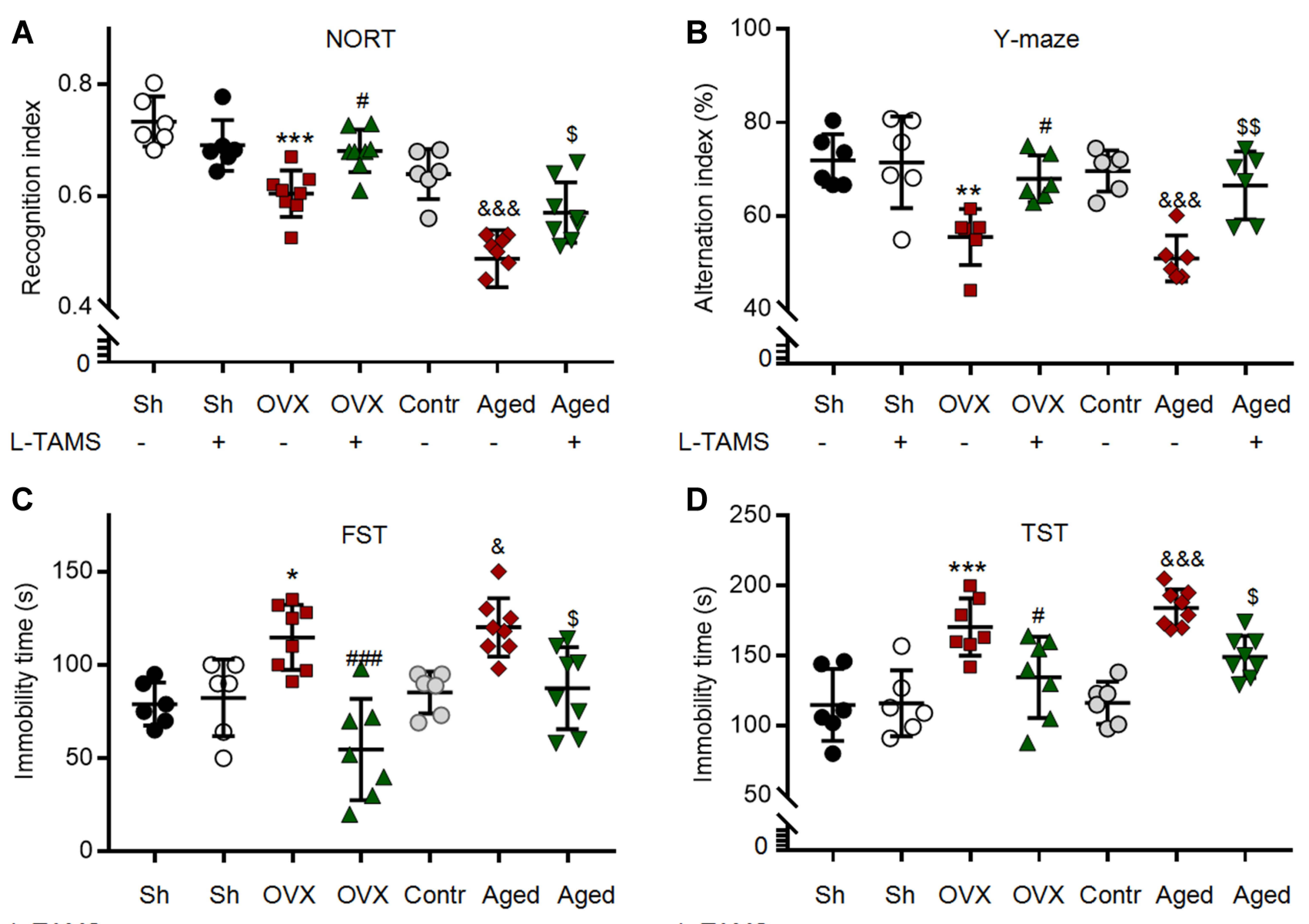

L-TAMS - $\quad+\quad-\quad+\quad-\quad-\quad+$

L-TAMS

Figure 3 Oral application of L-TAMS attenuates the memory/emotional deficits in both ovariectomized and aged female mice. (A) The recognition indexes assessed with the novel object recognition test (NORT) in indicated groups are shown ( $n=6-8$ per group). (B) The scatter diagram shows the alternation index (\% of total triplet arm entries) measured with the Y-maze test ( $n=6$ per group). (C and D) Immobility time in each group was measured in the forced swimming test (C) and tail suspension test

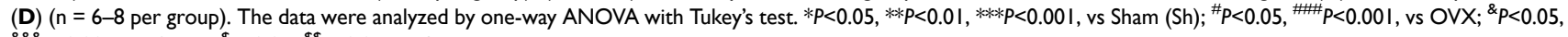
\&\&\& $P<0.00$ I, vs Contr; ${ }^{\$} P<0.05,{ }^{\$ \$} P<0.01$, vs Aged.

As no difference in the pain hypersensitivity (Figure 2), memory function and emotional behaviors (Figure 3) between control and sham mice were detected, in the following experiments, the data from the two groups were pooled together.

\section{Oral L-TAMS Depresses the} Neuroinflammation in Dorsal Root Ganglion and Spinal Dorsal Horn in Ovariectomized and Aged Mice

Previous works show that neuroinflammation in pain pathways, characterized by activation of $\mathrm{TNF}-\alpha / \mathrm{NF}-\kappa \mathrm{B}$ pathway and glial activation, plays a key role in the development of persistent pain induced by peripheral nerve injury, ${ }^{40,41}$ chemotherapy ${ }^{11,12}$ and high frequency noxious stimulation. ${ }^{5}$ We, therefore, tested if oral
L-TAMS is capable of depressing the neuroinflammation in dorsal root ganglion (DRG) and spinal dorsal horn in OVX and aged mice. We found that levels of phospho-p65 ( $p$-p65, an active form of NF- $\mathrm{B}$, Figure 4A), TNF- $\alpha$ (Figure 4B) and IL-1 $\beta$ (Figure 4C) in DRG neurons were significantly higher in OVX and aged mice compared to sham mice, and the changes were substantially prevented by oral L-TAMS (Figure 4D).

The Western blots with spinal dorsal horn tissue showed that TNF- $\alpha$, IL- $1 \beta, p$-p65 and $p$-I $\kappa \mathrm{B} \alpha$, were significantly upregulated in both OVX (Figure 5A and $\mathrm{C}$ ) and aged female mice (Figure 5B and D) compared to sham mice treated with vehicle. The molecular changes were, again, substantially attenuated by oral L-TAMS (Figure 5A-D). Double immunostaining revealed that $p$-p65 and TNF- $\alpha$ were heavily co-localized with NeuN (a marker for neuron), sparsely with Ibal (a marker for 


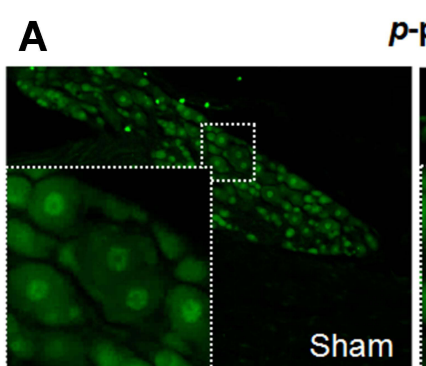

\section{p-p65}
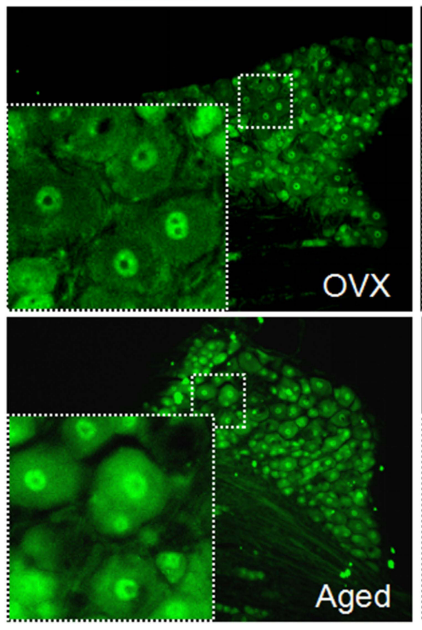

C

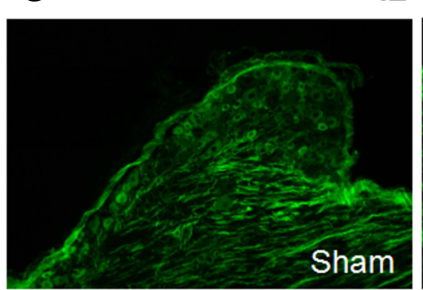

IL-1 $\beta$
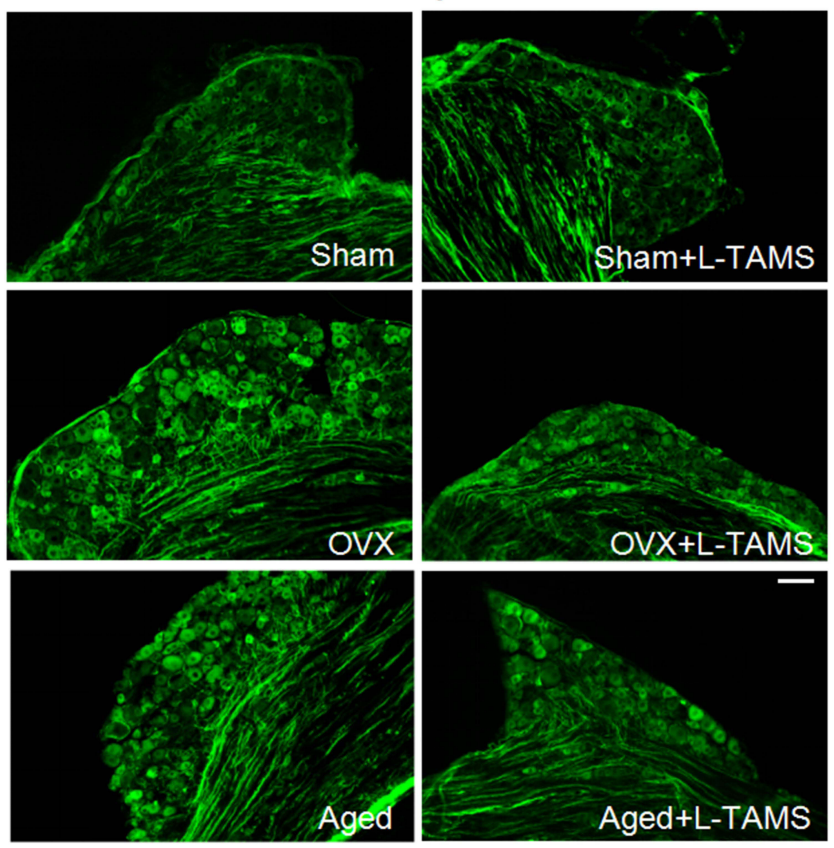

B TNF- $\alpha$
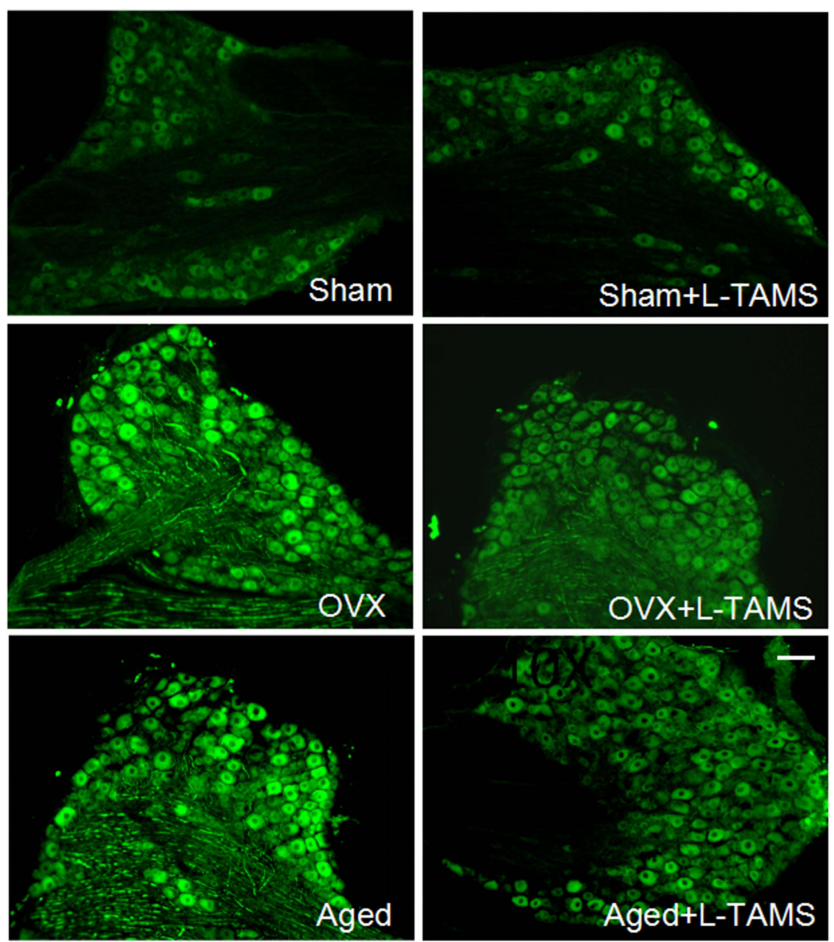

D
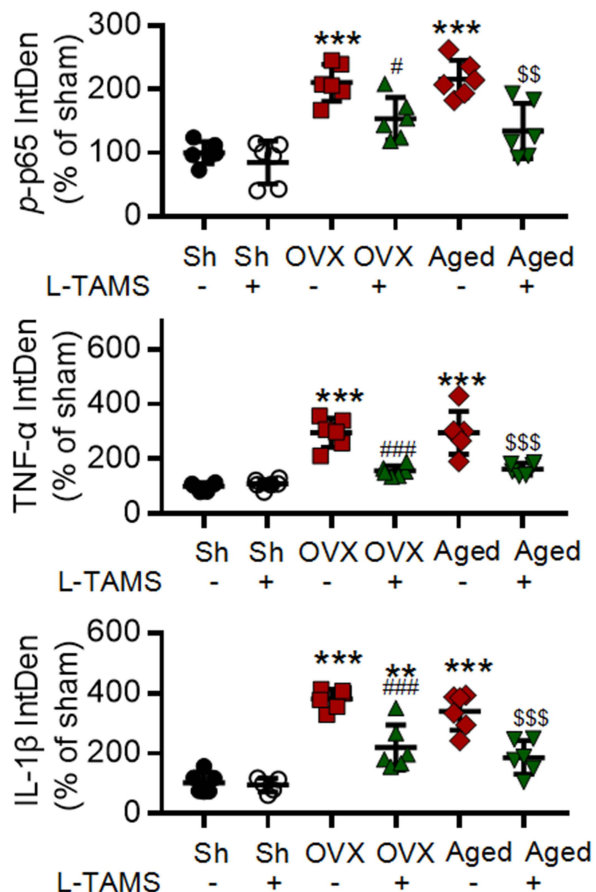

Figure 4 Oral application of L-TAMS attenuates the activation of NF- $\mathrm{KB}$ and upregulation of TNF- $\alpha$ and IL-I $\beta$ in dorsal root ganglion (DRG) neurons of ovariectomized and aged mice. (A-C) Representative immunofluorescent staining images show the expressions of $p$-p65 (A), TNF- $\alpha$ (B) and IL-I $\beta$ (C) in DRG neurons in indicated groups. Notes: $p$-p65 is mainly located in nuclei, while TNF- $\alpha$ and IL-I $\beta$ in cytoplasm and nerve fibers. Scale bar: $100 \mu$ m. (D) Statistical analysis revealed $p-p 65$, TNF- $\alpha$ and IL-I $\beta$ in DRG neurons were upregulated in OVX and aged mice, and the changes were attenuated by oral L-TAMS ( $\mathrm{n}=3$ mice/group, 2 sections/mouse). The data were analyzed by one-way ANOVA with Tukey's test. ${ }^{* * P} P<0.01$, ${ }^{* * *} P<0.00$ I, vs Sham $(\mathrm{Sh}) ;{ }^{\#} P<0.05,{ }^{\# \#} P<0.00$ I, vs OVX; ${ }^{\$ \$} P<0.01$, ${ }^{\$ \$ \$} P<0.00$ I, vs Aged.

microglial cell) and GFAP (a marker for astrocyte) (Figure 5E and F). Interestingly, IL-1 $\beta$ was co-localized with IB4 (a marker for non-peptidergic C-fibers) and
CGRP (a marker for peptidergic C-fibers) in superficial spinal dorsal horn (Figure 5H), sparsely with GFAP and Iba1, but not with NeuN (Figure 5G). 

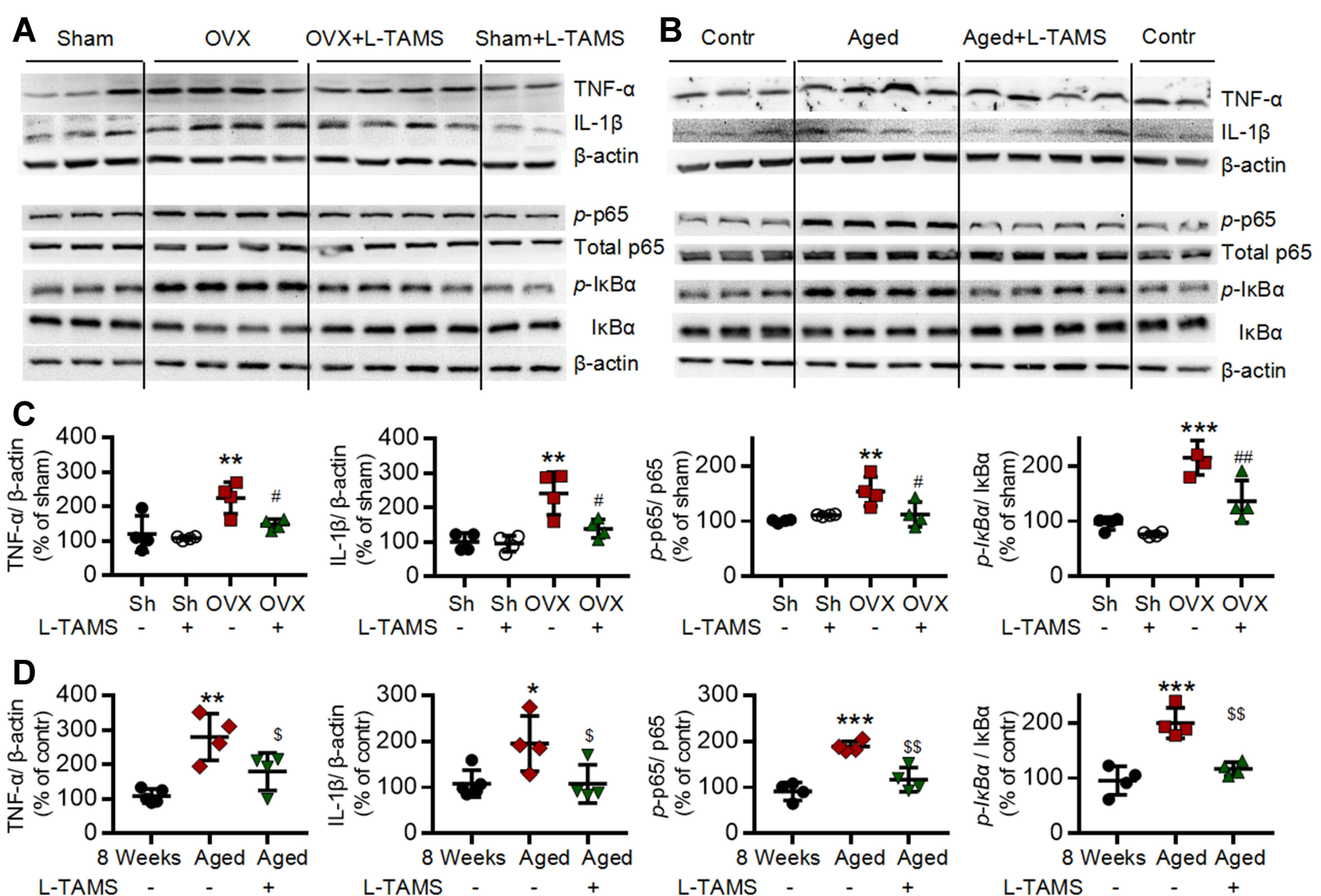

\section{E}

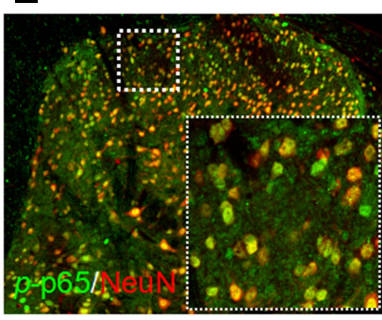

F
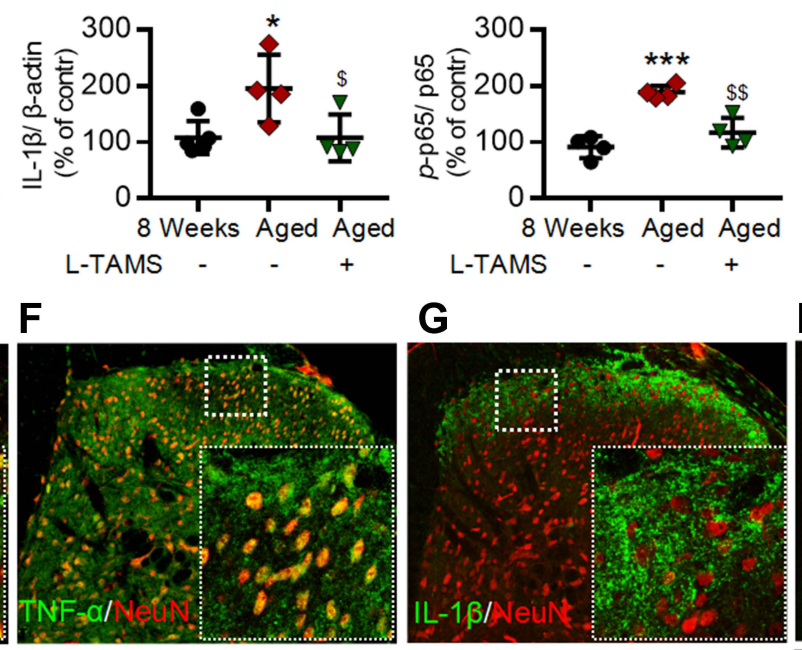

L-TAMS

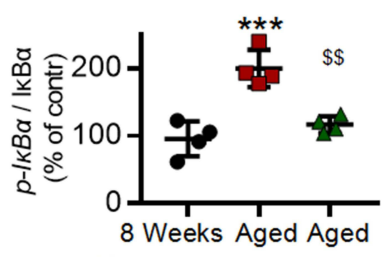

G

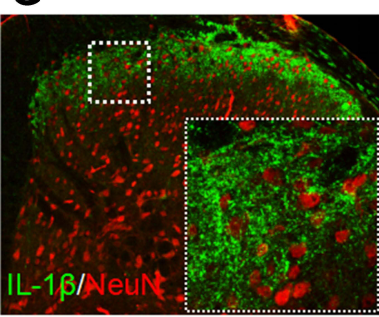

H L-TAMS
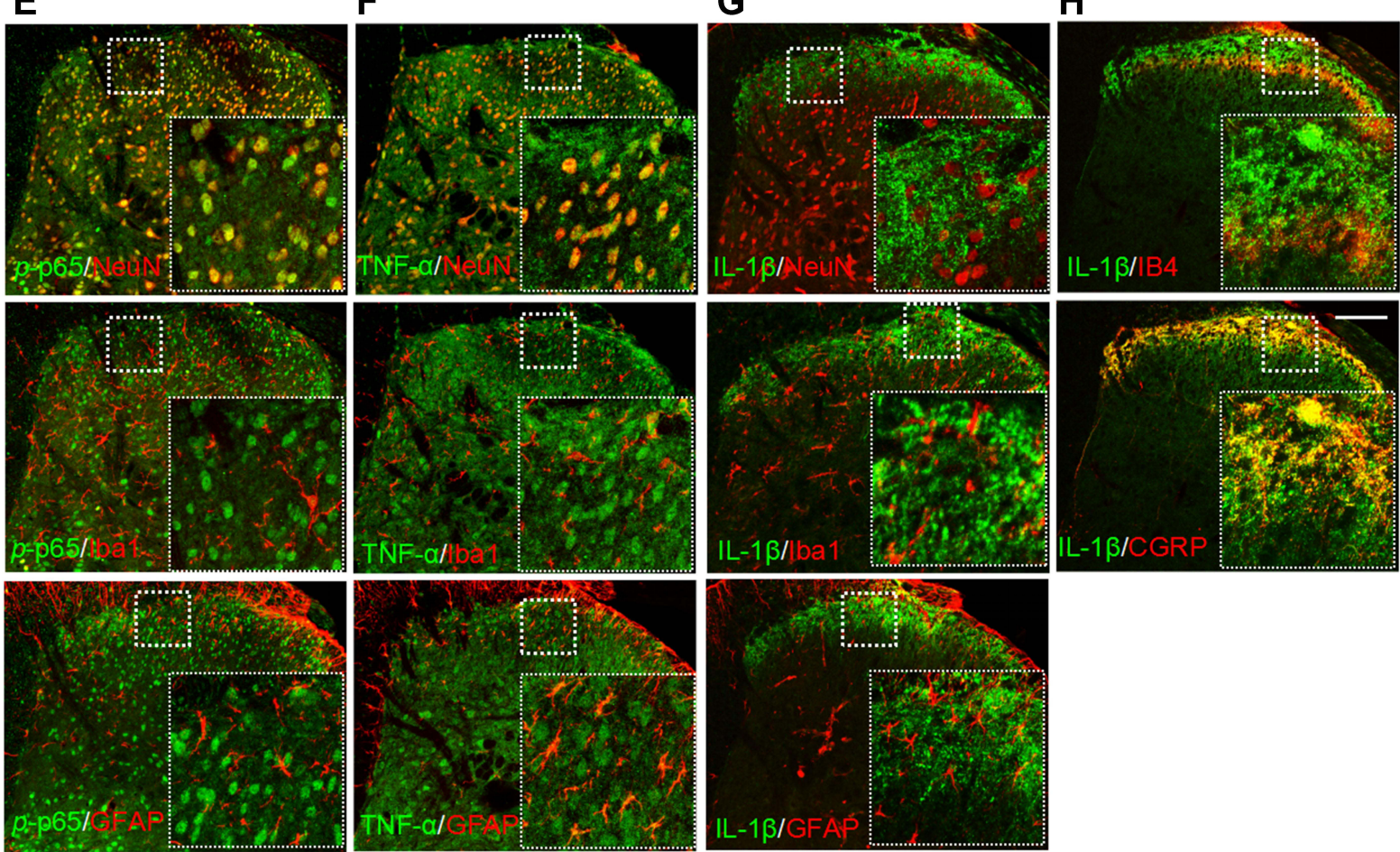

Figure 5 Oral L-TAMS inhibits the activation of NF- $\mathrm{KB}$ and upregulation of TNF- $\alpha$ and IL-I $\beta$ in spinal dorsal horn of ovariectomized and aged mice. (A and C) Representative Western blots (A) and statistical analysis (C) show the protein levels of TNF- $\alpha$, IL-I $\beta, p$-p65, total p65, $p$-IKB $\alpha$ and IKB $\alpha$ in spinal dorsal horn in Sham, Sham + L-TAMS, OVX, and OVX + L-TAMS groups ( $n=4$ per group). (B and D) Representative Western blots (B) and statistical analysis (D) show the levels of TNF- $\alpha$, IL-I $\beta, p$-p65, total $p 65$, $p$-IKB $\alpha$ and IKB $\alpha$ in spinal dorsal horn in control ( 8 weeks), Aged and Aged + L-TAMS groups ( $n=4-5$ per group). The data were analyzed by one-way ANOVA with Tukey's test. $* P<0.05$, $* * P<0.0$ I, $* * * P<0.00$ I, vs Sham (Sh); ${ }^{\#} P<0.05,{ }^{\#} P<0.01$ vs OVX; ${ }^{\$} P<0.05,{ }^{\$ \$} P<0.01$ vs Aged. $(\mathbf{E}-\mathbf{H})$ Representative confocal images of the double immunofluorescence staining show that $p$ - $p 65(\mathbf{E})$ and TNF- $\alpha(\mathbf{F})$ is mainly located in the nuclei and cytoplasm of dorsal horn neurons respectively, they are also expressed in small amounts in microglia (Iba I) and astrocytes (GFAP); The IL-I $\beta$ (G and $\mathbf{H})$ is mainly located in $\mathrm{CGRP}^{+}$terminals but not in spinal dorsal horn neurons. Scale bar: $100 \mu \mathrm{m}$. 
To investigate if the proinflammatory cytokines TNF- $\alpha$ and IL- $1 \beta$ are synthesized in the neurons of DRG and spinal dorsal horn, we detected their mRNAs with in situ hybridization. We found that Tnf and Il-1 $\beta$ were located in the cytoplasm of DRG (Figure 6A and $\mathrm{B}$ ) and dorsal horn (Figure 6C and D) neurons in OVX and aged mice.

We found that both microglia and astrocytes were activated in OVX and aged female mice treated with vehicle, as both intensities of Iba1 and GFAP (Figure 7A-D), and the numbers of Iba1- and GFAPpositive cells (Figure 7E and F) were significantly increased in these mice, compared to sham ones. The glial activation in OVX and aged mice was remarkedly prevented or reversed by L-TAMS (Figure 7A-F).

Our previous works show that chemotherapy ${ }^{10}$ and higher frequency noxious stimuli ${ }^{5}$ that induce persistent pain upregulates CGRP (a marker for peptidergic C-fiber) in spinal dorsal horn. In the present work, we found that in OVX and aged female mice CGRP but not isolectin B4 (IB4, a marker for nonpeptidergic C-fiber) were also upregulated in the spinal dorsal horn, and oral application of L-TAMS prevented and reversed the CGRP upregulation in OVX mice and aged mice, respectively (Figure 8A-D). Western blots confirmed that oral L-TAMS depressed the upregulation of CGRP in the spinal dorsal horn (Figure $8 \mathrm{E}-\mathrm{H}$ ). We found that CGRP was co-localized with $p$-p65, TNF- $\alpha$ and IL-1 $\beta$ in DRG neurons of OVX mice (Figure 8I), indicating that the upregulation of CGRP is associated with neuroinflammation.

\section{Oral L-TAMS Depresses the Neuroinflammation in Hippocampi of Ovariectomized and Aged Mice}

As neuroinflammation plays a key role in memory and emotional deficits in a variety of disease models, such as peripheral nerve injury, ${ }^{7}$ chemotherapy, ${ }^{11,12}$ Alzheimer disease, ${ }^{42}$ and mood depression, ${ }^{43,44}$ we next investigated if the neuroinflammation also exists in hippocampi of OVX and aged mice. We found that TNF- $\alpha$, IL- $1 \beta$, $p$-p65, and $p$-IкB $\alpha$ in the hippocampi were significantly higher in both OVX and aged female mice than those in sham mice in vehicle-treated groups, and the changes were significantly attenuated by oral L-TAMS (Figure 9A-D). Double immunostainings (Figure 9E-G) showed that $p$-p65, TNF- $\alpha$ or IL- $1 \beta$ was mainly co-localized with
NeuN, sparsely with Iba1 and GFAP. We found that both intensities of Ibal and GFAP (Figure 10A-D), and the numbers of Iba1- and GFAP-positive cells in hippocampi (Figure 10E and F) were significantly increased in both OVX and aged female mice, compared to sham mice in vehicle-treated groups. Interestingly, we found that the glial activation induced by OVX or aged was remarkedly prevented and reversed by oral L-TAMS (Figure 10A-F). The data suggest that oral L-TAMS may attenuate the memory and emotional deficits in OVX and aged female mice by inhibition of neuroinflammation.

\section{The Estrogen Decline Causes}

\section{Neuroinflammation Through Producing Magnesium Deficiency in Ovariectomized and Aged Female Mice}

Clinical data show that serum $\mathrm{Mg}^{2+}$ is decreased in postmenopausal women. ${ }^{15,16}$ Our data demonstrated that supplement $\mathrm{Mg}^{2+}$ by chronic oral application of L-TAMS substantially attenuated the chronic pain sensitivity, memory/emotional deficits as well as neuroinflammation in either OVX or aged mice. We, therefore, hypothesized that estrogen decline may cause neuroinflammation by producing $\mathrm{Mg}^{2+}$ deficiency. To test this, we first determine if $\mathrm{Mg}^{2+}$ is really reduced in OVX and old mice. We found that free $\mathrm{Mg}^{2+}$ in serum and CSF was significantly lower in both OVX and aged mice in vehicle-treated groups (Figure $11 \mathrm{~A}$ and $\mathrm{B}$ ). As $31 \%$ of $\mathrm{Mg}^{2+}$ in the body is distributed inside cells, where it functions as a coactivator for 600 enzymes, ${ }^{24}$ the change in intracellular $\mathrm{Mg}^{2+}$ is more important for cell function. To determine if the intracellular $\mathrm{Mg}^{2+}$ is also reduced in the neuronal cells, we measured intracellular free $\mathrm{Mg}^{2+}$ in DRG neurons by flow cytometry (FCM) (Figure $11 \mathrm{C}$ and D), and found that the ion was also significantly lower in OVX and aged mice, compared to sham mice. The extracellular and intracellular $\mathrm{Mg}^{2+}$ deficiency induced by OVX and aged was attenuated by oral L-TAMS (Figure 11A-D). We found that the concentration of plasma estrogen was $18.8 \pm 3.3$ $\mathrm{ng} / \mathrm{L}$ in sham mice and is decreased significantly in OVX and aged mice. Oral L-TAMS did not affect plasma estrogen levels in sham, OVX and aged mice (Figure 11E).

To exam if the $\mathrm{Mg}^{2+}$ deficiency is caused by estrogen decline, we cultured DRG neurons with different concentrations of estrogen, and found that $17 \beta$-estrogen at a physiological concentration $(20 \mathrm{ng} / \mathrm{L}$ measured in adult sham mice, 


\section{Dorsal root ganglion}
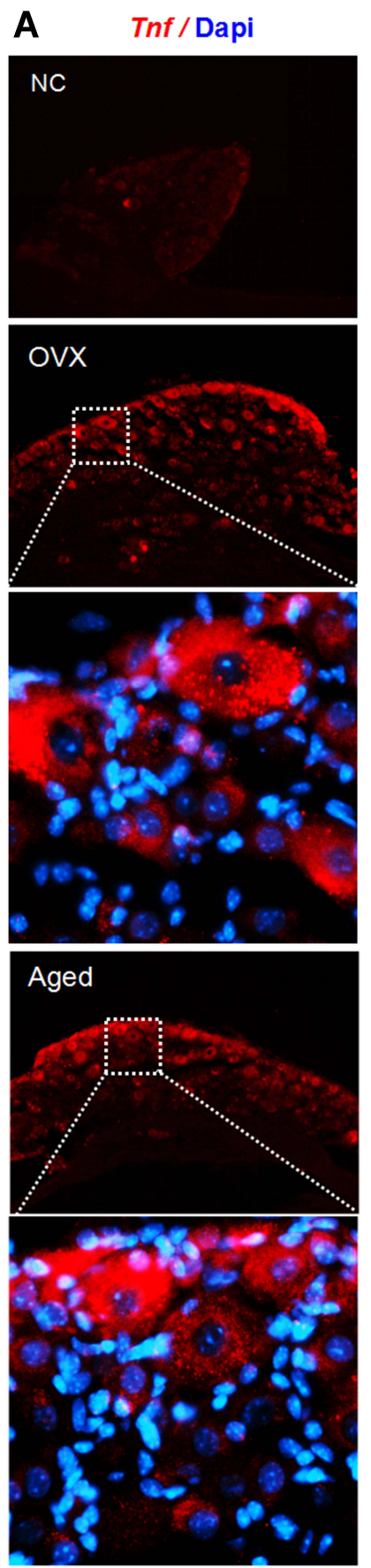
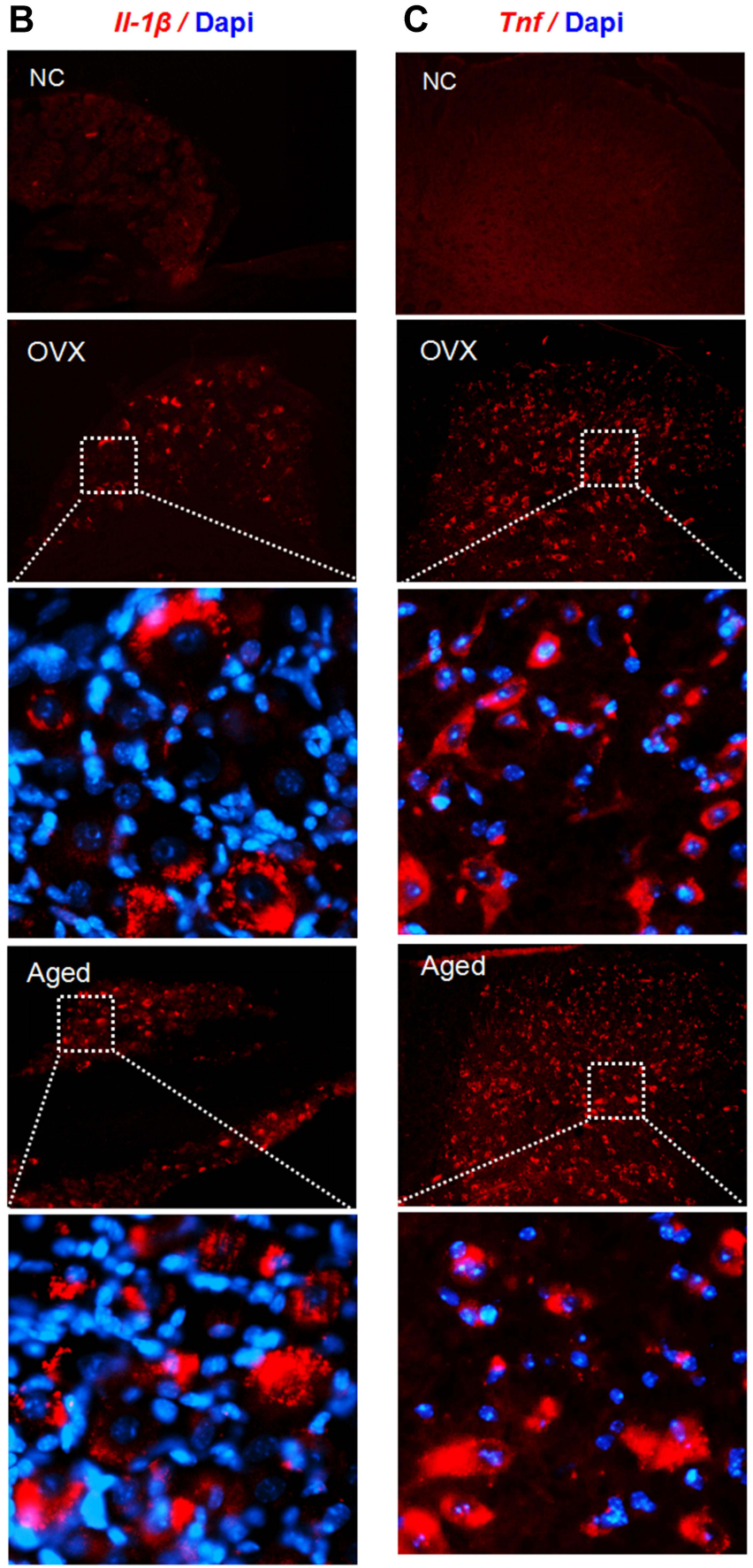

\section{Spinal cord}

D $\quad I /-1 \beta / D a p i$
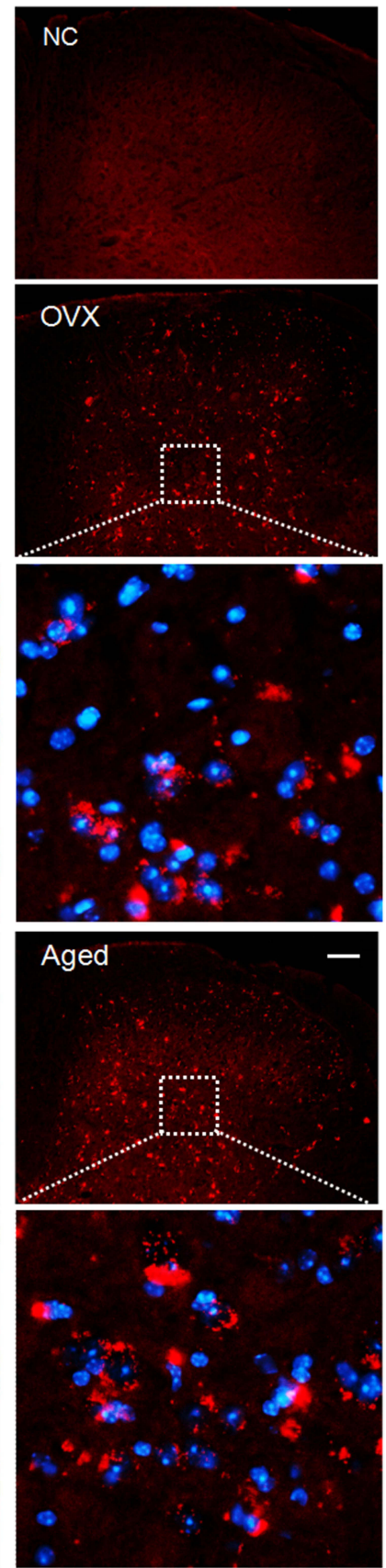

Figure 6 Tnf and II-I $\beta$ mRNAs are expressed in DRG and spinal dorsal horn neurons of OVX and aged mice. (A-D) In situ hybridization results show that both Tnf and III $\beta$ were located in cytoplasm of DRG neurons (A and $\mathbf{B})$ and spinal dorsal horn neurons (C and $\mathbf{D})$ of OVX and aged mice. The red dots are signals and blue ones Dapi. Scale bar: $100 \mu \mathrm{m}$.

Abbreviation: NC, negative control.

Figure 11E) but not at $5 \mathrm{ng} / \mathrm{L}$ significantly enhanced the intracellular free $\mathrm{Mg}^{2+}$ (Figure 12A). That is, intracellular $\mathrm{Mg}^{2+}$ is regulated by extracellular estrogen. Finally, we investigated if the $\mathrm{Mg}^{2+}$ deficiency resulting from estrogen decline may activate TNF- $\alpha / \mathrm{NF}-\kappa \mathrm{B}$ pathway in cultured DRG neurons. As shown in Figure 12B and D, in normal culture medium that containing $\mathrm{Mg}^{2+}, 17 \beta$-estrogen at $20 \mathrm{ng} / \mathrm{L}$ but not $5 \mathrm{ng} / \mathrm{L}$ downregulated $p$-p65, TNF- $\alpha$ and IL-1 $\beta$. While in magnesium- 

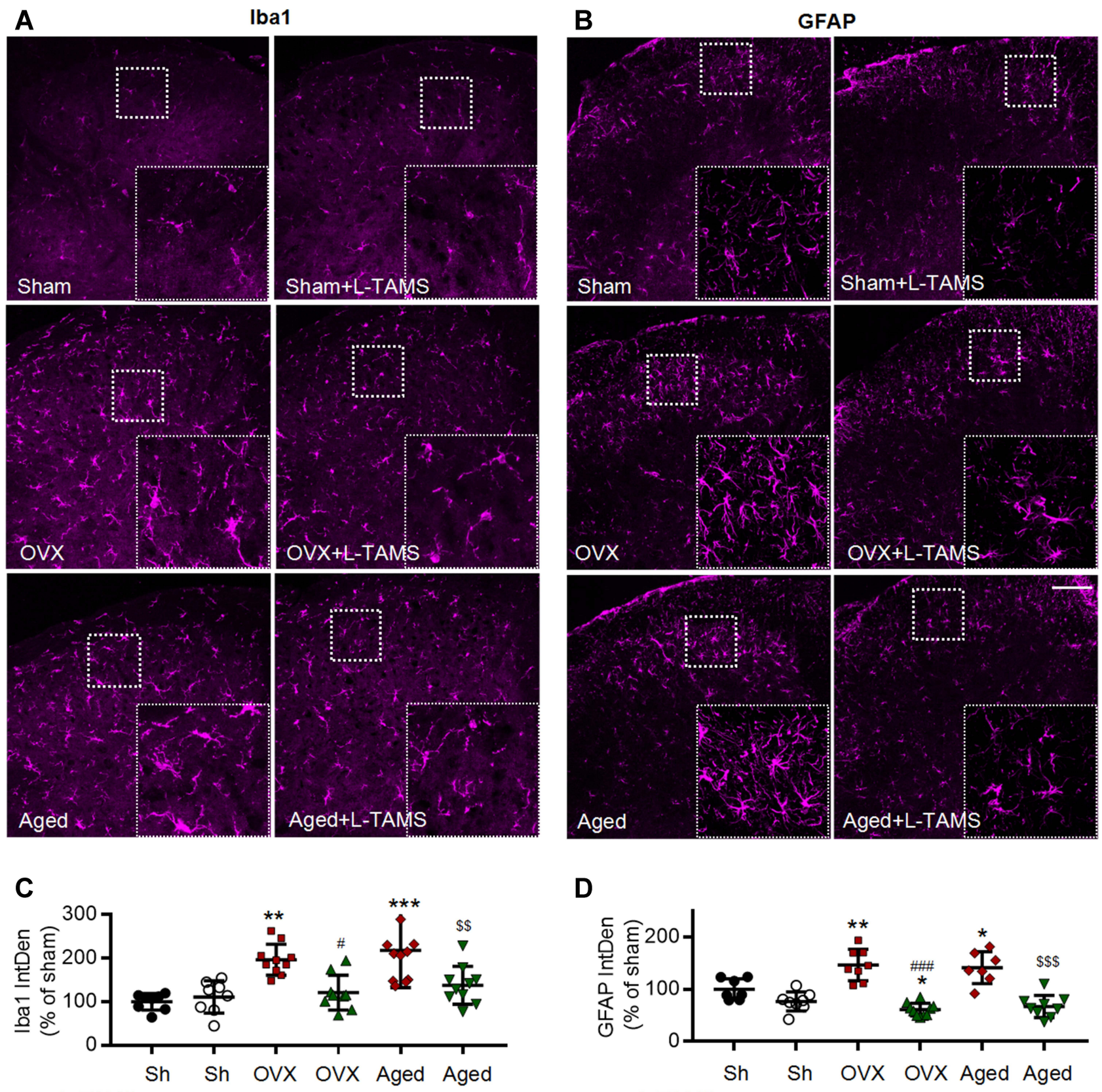

D
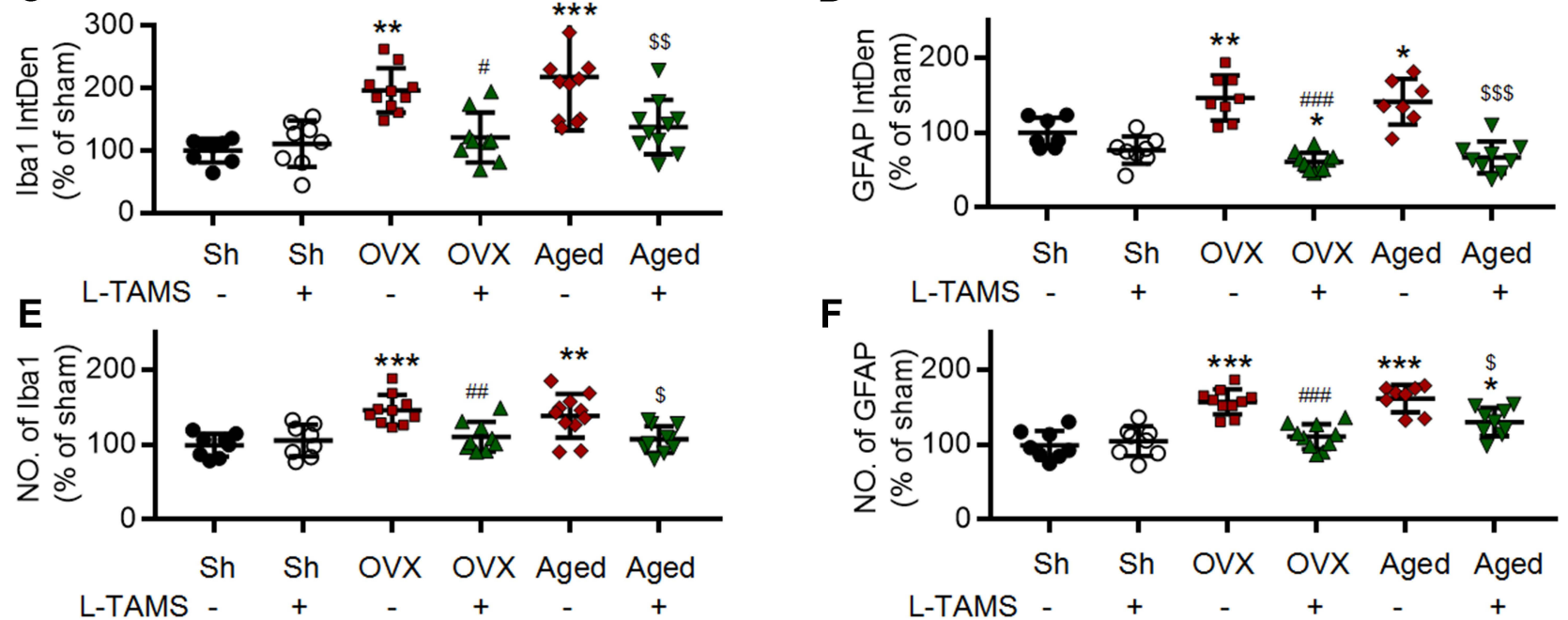

Figure 7 Oral application of L-TAMS inhibits the activation of microglia and astrocytes in spinal dorsal horn in OVX and aged mice. (A and B) Representative confocal images of the immunofluorescence staining of Ibal (A) and GFAP (B) in spinal dorsal horn of different groups. Scale bar: $100 \mu \mathrm{m}$. (C and D) Statistical analysis of immunofluorescence intensity of Ibal (C) and GFAP (D) in different groups ( $n=3-4$ mice/group, 2-3 sections/mouse). (E and $\mathbf{F})$ The count of lbal $\left.\right|^{+}$cell (E) and GFAP ${ }^{+}$cell (F) in each 20x field were statistically analyzed ( $n=3-4$ mice/group, $2-3$ sections/mouse). The data were analyzed by one-way ANOVA with Tukey's test. *P<0.05, $* * P<0.01$,

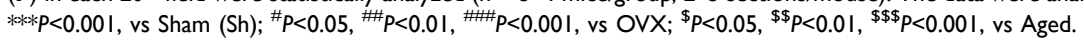


A

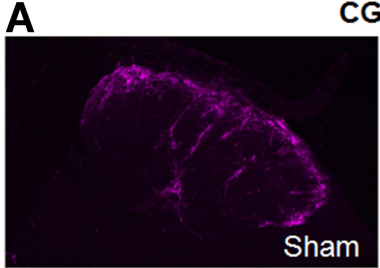

CGRP
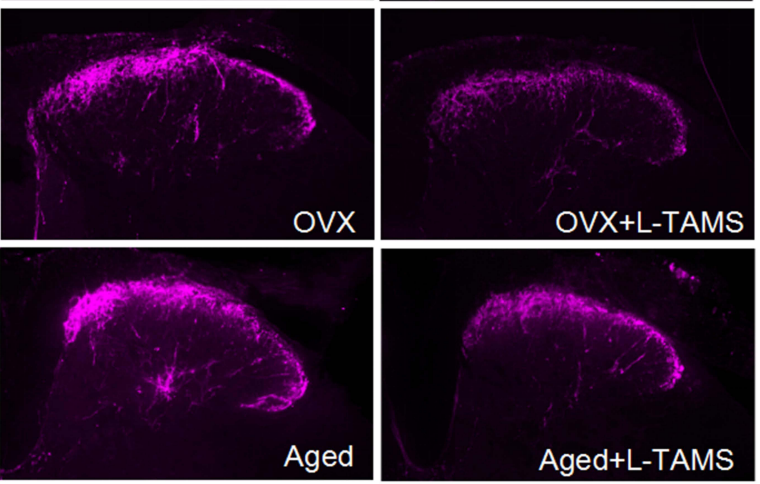

C

L-TAMS
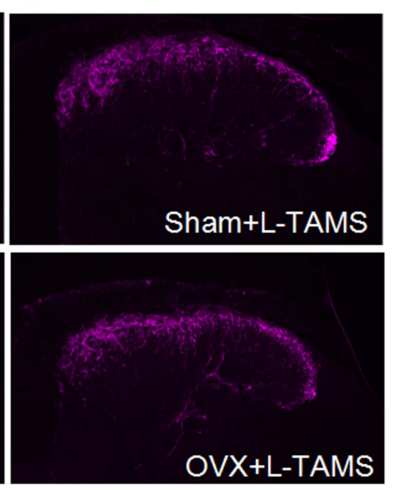

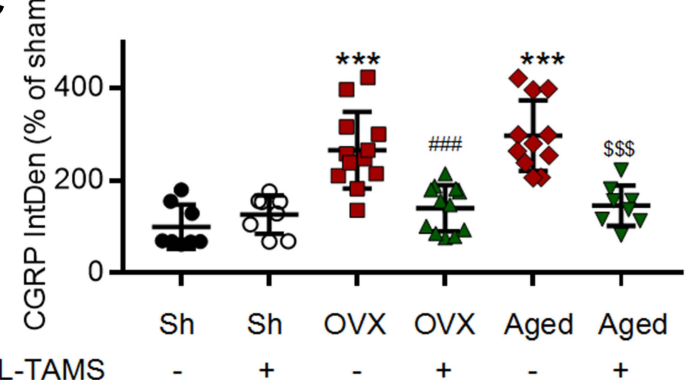

E

E Sham

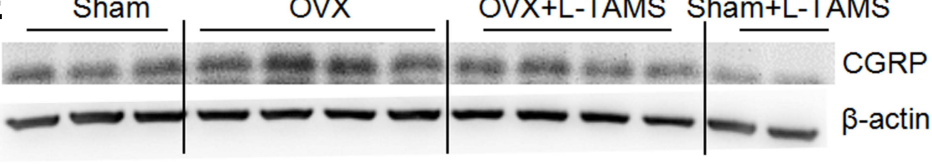

G

G Contr

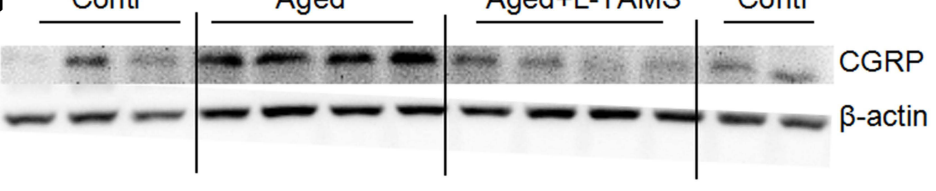

I
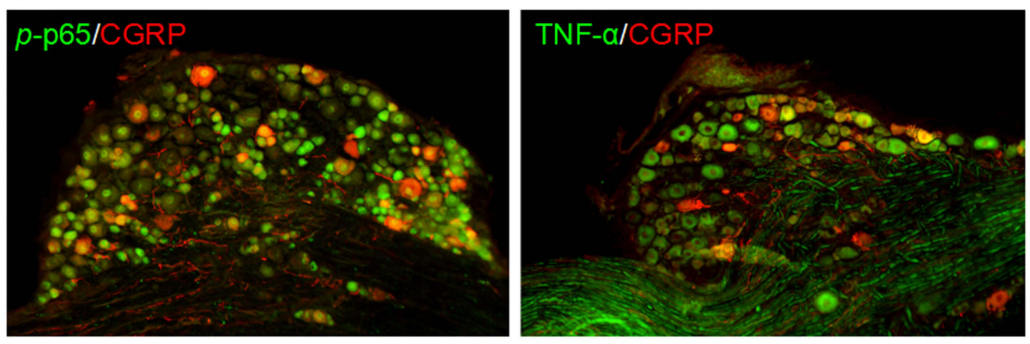

B

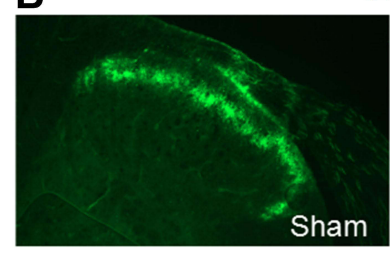

IB4
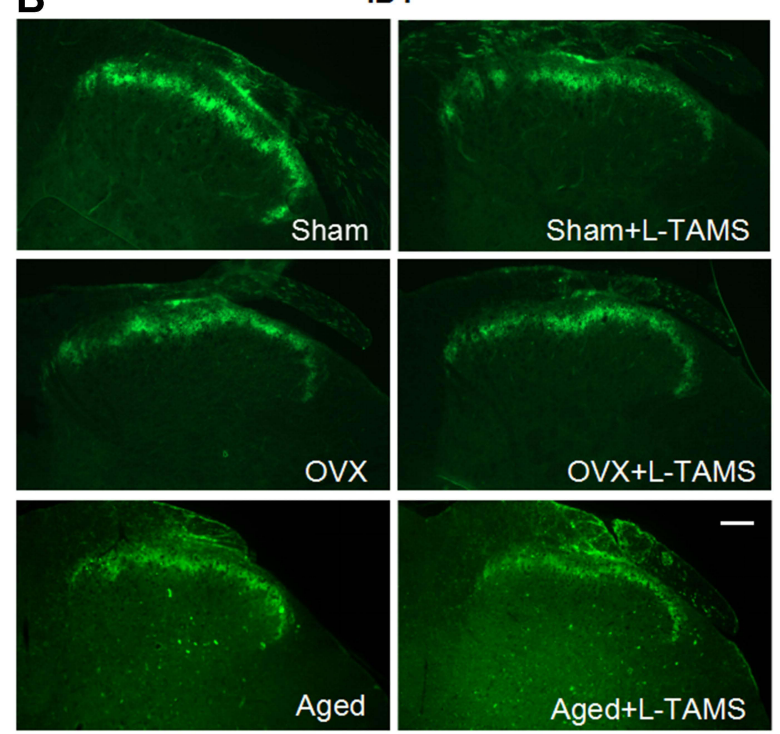

D

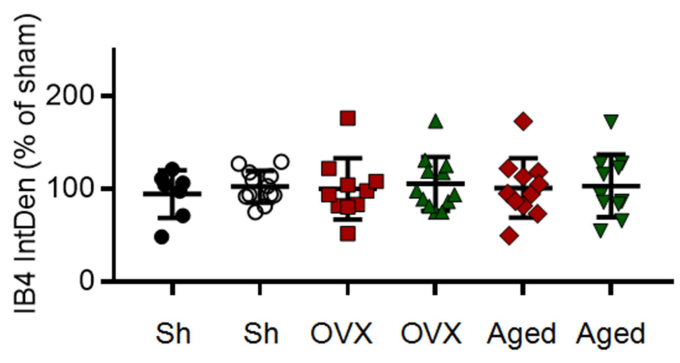

L-TAMS
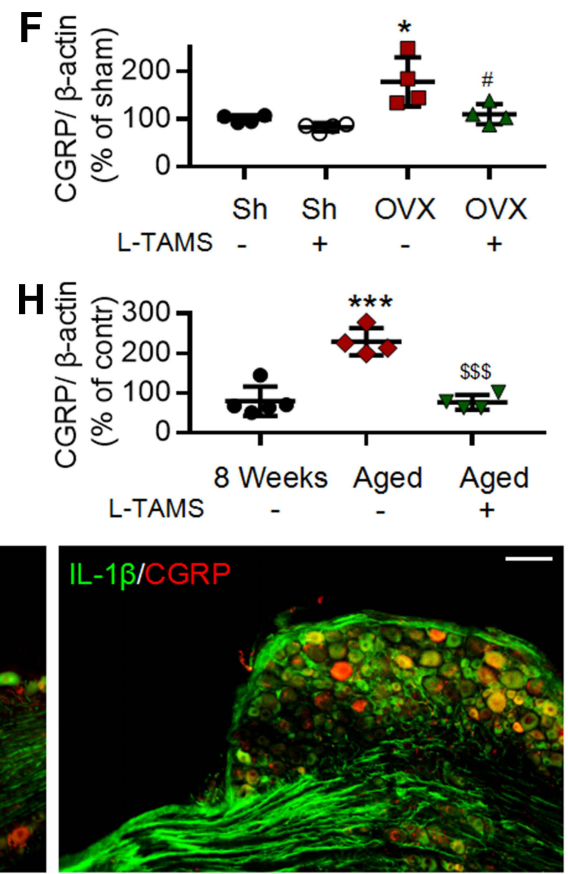

Figure 8 Oral application of L-TAMS prevents the CGRP increase in ovariectomized mice and reverses the CGRP increase in aged female mice in spinal dorsal horn. (A and B) Representative immunofluorescent staining images of CGRP (A) and IB4 (B) in spinal dorsal horn of different groups. Scale bar: I00 $\mu \mathrm{m}$. (C and D) Oral application of L-TAMS significantly attenuates the CGRP sprouting in OVX and aged mice. There was no significant difference in the expression of IB4 among the groups ( $\mathrm{n}=3-4$ mice/group, 2-3 sections/ mouse). (E and F) Representative Western blots (E) and statistical analysis (F) show the CGRP levels in spinal dorsal horn in Sham, Sham + L-TAMS, OVX, and OVX+ L-TAMS groups ( $\mathrm{n}$ $=4$ per group). $(\mathbf{G}$ and $\mathbf{H})$ Representative Western blots $(\mathbf{G})$ and statistical analysis $(\mathbf{H})$ show the CGRP levels in spinal dorsal horn in control (8 weeks), Aged and Aged + L-TAMS groups ( $n=4-5$ per group). The data were analyzed by one-way ANOVA with Tukey's test. ${ }^{* P}<0.05,{ }^{* * * P<0.00 I}$, vs Sham (Sh); ${ }^{\#} P<0.05,{ }^{\#+1} P<0.00 \mathrm{I}$, vs OVX; ${ }^{\$ \$ \$} P<0.00 \mathrm{I}$, vs Aged. (I) Double stainings show that CGRP is colocalized with $p-p 65$, TNF- $\alpha$ and IL-I $\beta$ in DRG neurons. Scale bar: $100 \mu \mathrm{m}$. 

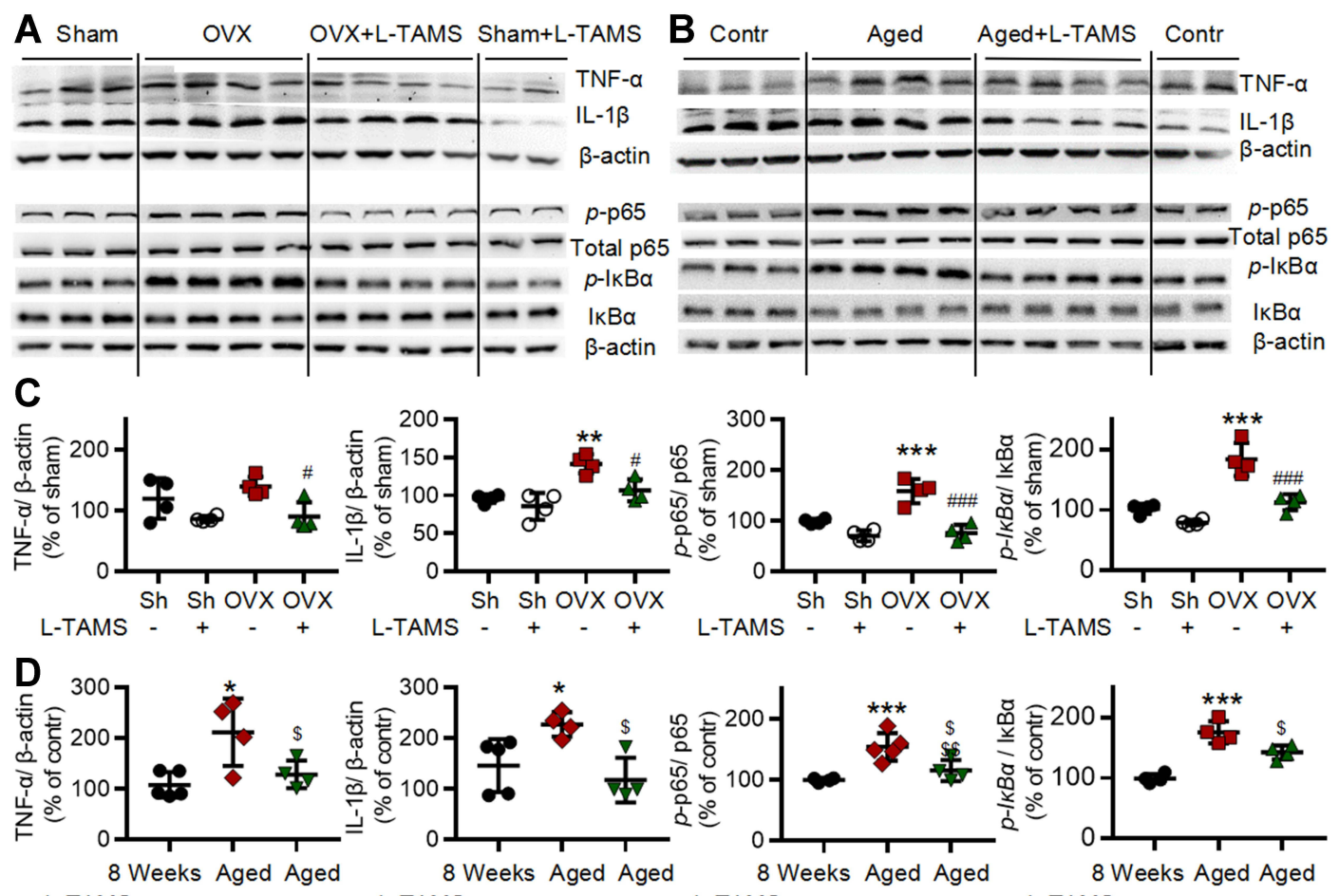

L-TAMS
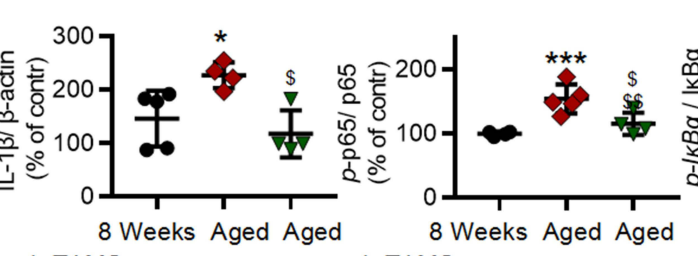

L-TAMS - + - +

E
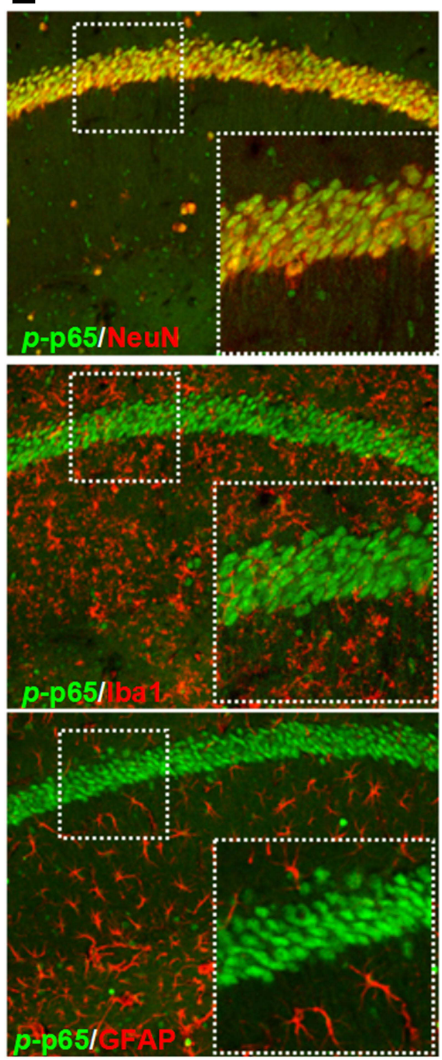

F

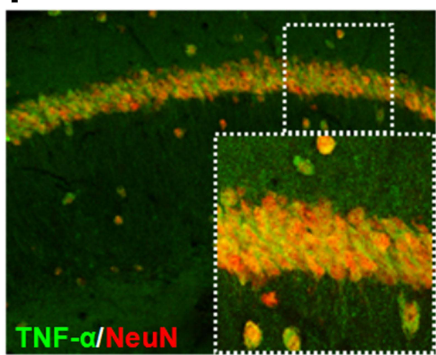

G
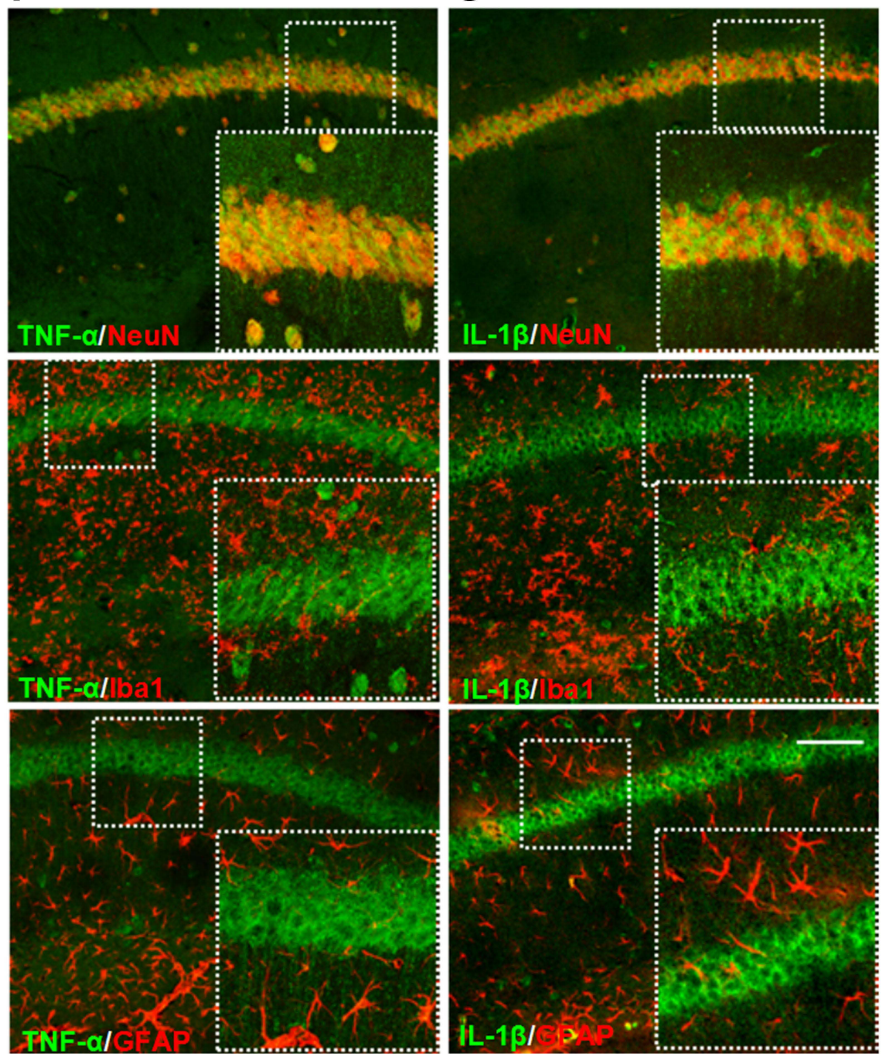

Figure 9 Oral application of L-TAMS attenuates the activation of NF-KB and upregulation of TNF- $\alpha$ and IL-I $\beta$ in hippocampal CAI region of ovariectomized and aged mice. $(\mathbf{A}$ and $\mathbf{C})$ Representative Western blots (A) and statistical analysis (C) show the protein levels TNF- $\alpha$, IL-I $\beta, p-p 65$, total $p 65$, $p$-IKB $\alpha$ and IKB $\alpha$ in hippocampi in indicated groups ( $n=4$ per group). (B and D) Representative Western blots (B) and statistical analysis (D) show the protein levels of TNF- $\alpha$, IL-I $\beta, p-p 65$, total p65, $p$-IKB $\alpha$ and IKB $\alpha$ in hippocampi of control ( 8 weeks), Aged and Aged + L-TAMS groups $(n=4-5$ per group). The data were analyzed by one-way ANOVA with Tukey's test. $* P<0.05$, $* * P<0.01$, ${ }^{*} * * P<0.001$, vs Sham (Sh); ${ }^{\#} P<0.05,{ }^{\#} P<0.01$, vs OVX; ${ }^{\$} P<0.05,{ }^{\$} P<0.01$, vs Aged. (E-G) Representative confocal images of the double immunofluorescence staining show that p-p65 (E) is mainly located in the nuclei of hippocampal CAI neurons. TNF- $\alpha(\mathbf{F})$, and IL-I $\beta(\mathbf{G})$ are mainly located in the cytoplasm of hippocampal CAI neurons. Scale bar: $100 \mu \mathrm{m}$. 
A
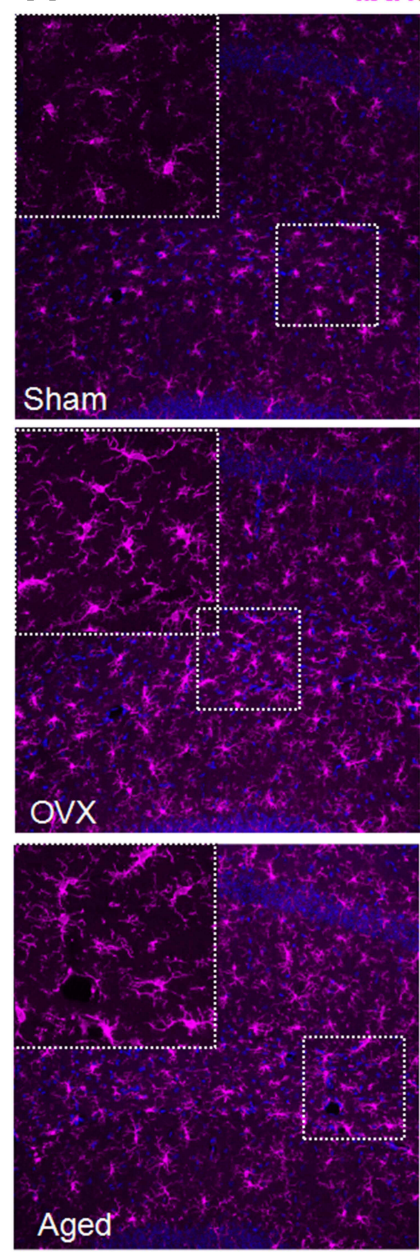

C
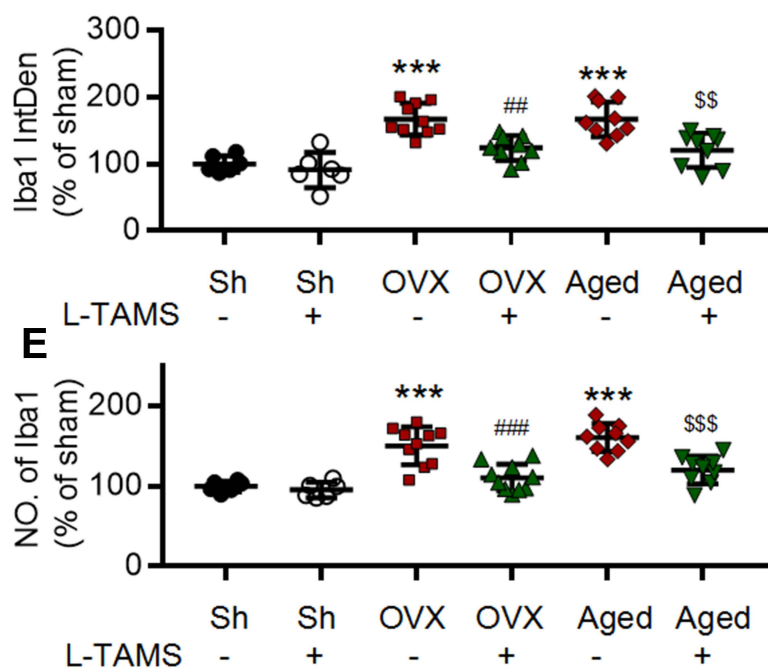

B GFAP/Dapi
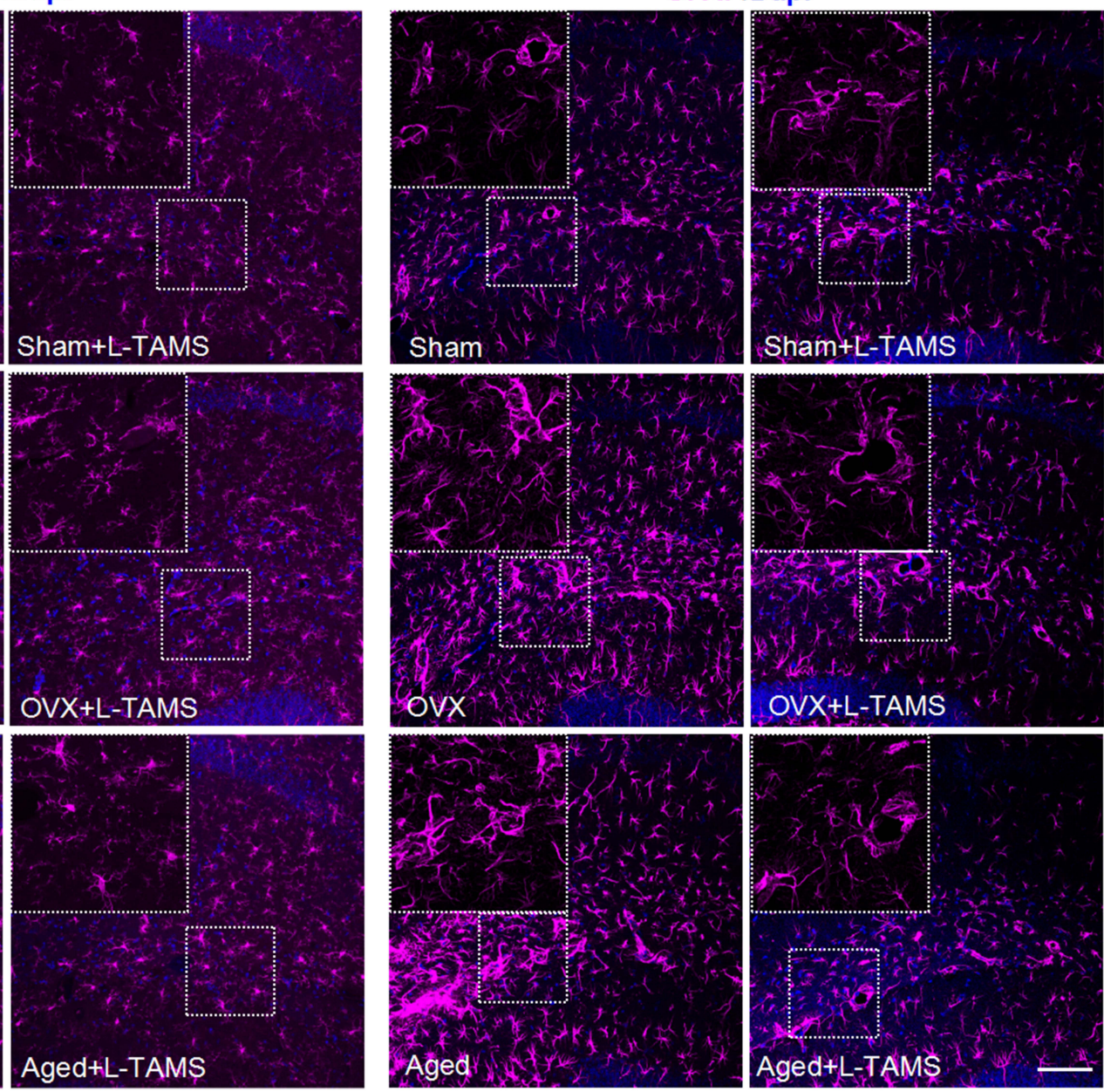

Sham
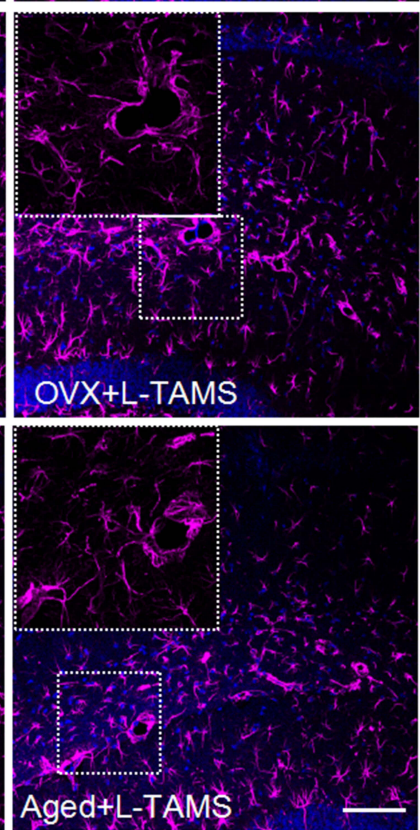

D

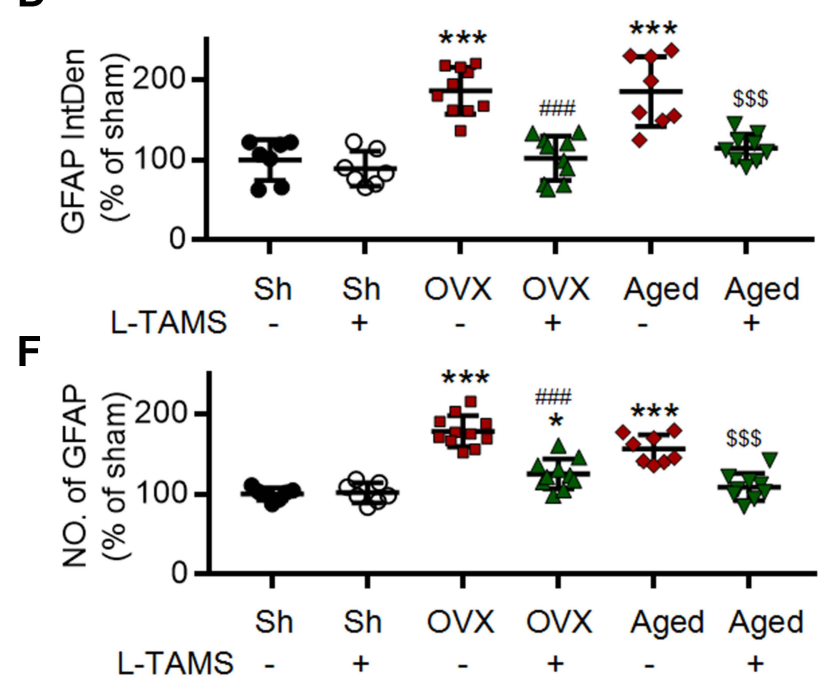

Figure 10 Oral application of L-TAMS attenuates the activation of microglia and astrocytes in hippocampi induced by ovariectomy and aged. (A and B) Representative confocal images of the immunofluorescence staining of Ibal (A) and GFAP (B) in the different groups as indicated, Scale bar: I00 $\mu$ m. (C and D) Statistical analysis of immunofluorescence intensity of lbal (C) and GFAP (D) in hippocampal of different groups ( $\mathrm{n}=3-4$ mice/group, $2-3$ sections/mouse). (E and $\mathbf{F})$ The count of lba I ${ }^{+}$cell (E) and GFAP ${ }^{+}$cell $(\mathbf{F})$ in each $20 \times$ field were statistically analyzed $(n=3-4$ mice/group, $2-3$ sections/mouse). The data were analyzed by one-way ANOVA with Tukey's test.

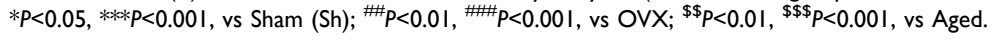



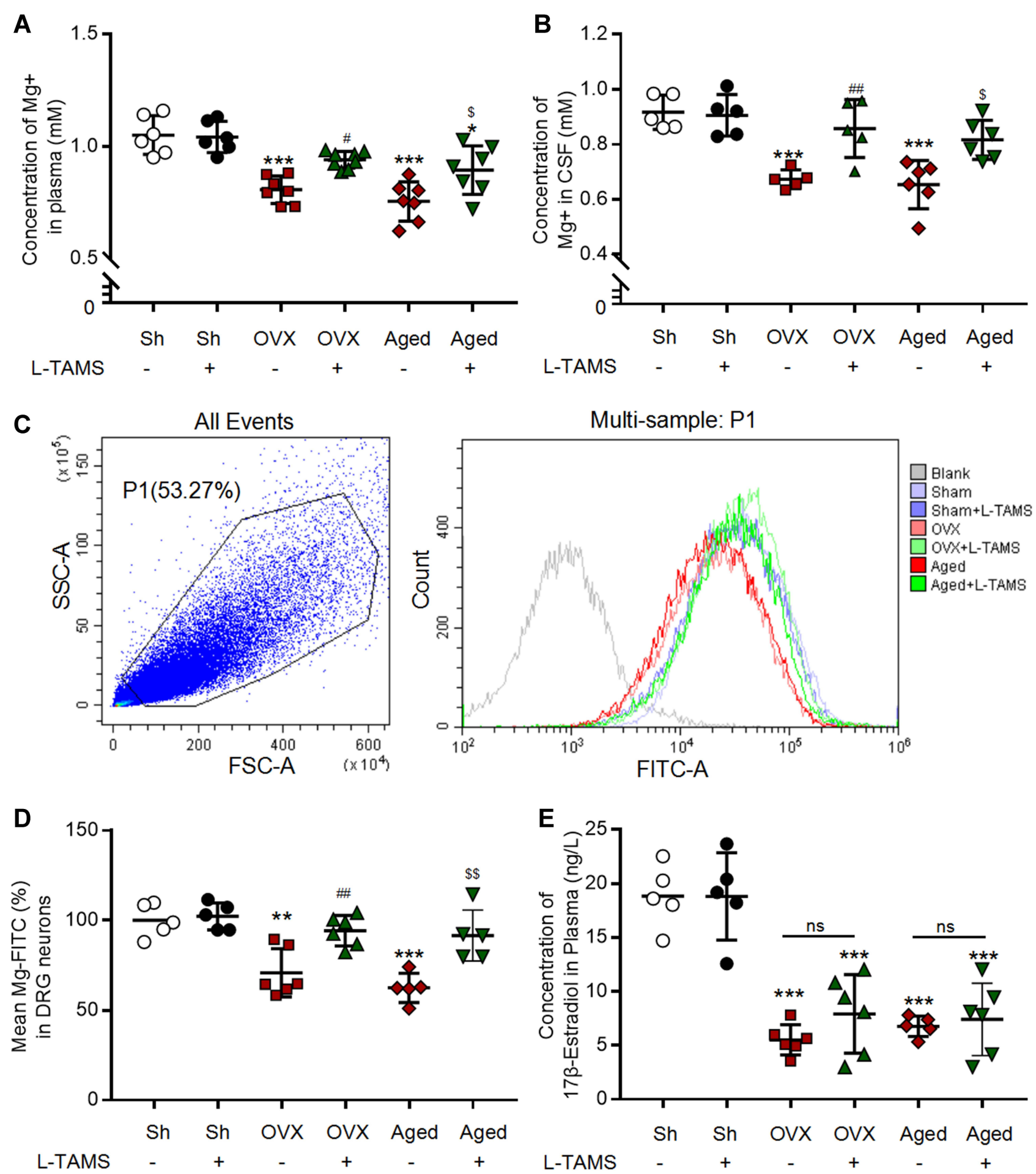

L-TAMS

Figure I I Oral L-TAMS attenuates magnesium deficits but not estrogen decline in ovariectomized and aged female mice. (A and $\mathbf{B})$ Free $\mathrm{Mg}^{2+}$ concentrations in the plasma $((\mathbf{A}), n=6-8$ per group) and CSF $((\mathbf{B}), n=5-6$ per group) in indicated groups are shown. $(\mathbf{C}$ and $\mathbf{D})$ Representative flow physical diagram $(\mathbf{C})$ and scatter diagram $(\mathbf{D})$ show the level of intracellular free magnesium of DRG neurons (assessed as mean fluorescence intensity of 30,000 cells per mice) ( $n=5-6$ per group). (E) The plasma concentration of $17 \beta$-Estradiol in each group was measured by ELISA ( $n=5-6$ per group). The data were analyzed by one-way ANOVA with Tukey's test. $* P<0.05$, $* * P<0.01$, ****P<0.00I, vs Sham (Sh); ${ }^{\#} P<0.05,{ }^{\#} P<0.01$, vs OVX; ${ }^{\$} P<0.05,{ }^{\$ \$} P<0.01$, vs Aged.

Abbreviation: ns, not significant.

free medium 17ß-estrogen had no such effect at either of doses (Figure 12C and E). The data indicate that the anti-inflammation effect of $17 \beta$-estrogen is dependent on extracellular $\mathrm{Mg}^{2+}$.
Therefore, $\mathrm{Mg}^{2+}$ deficiency resulting from estrogen decline may, at least partially, contribute to neuroinflammation in OVX and aged mice. 


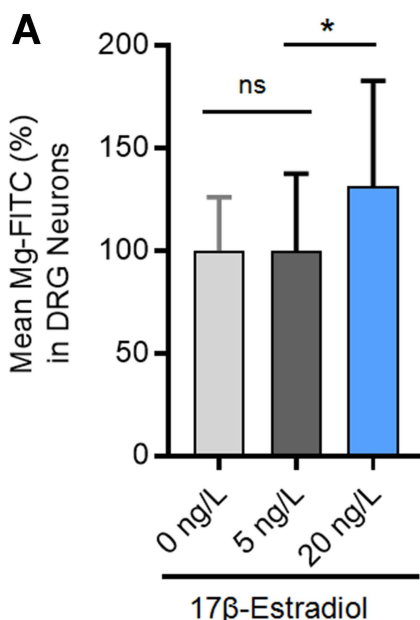

$17 \beta$-Estradiol
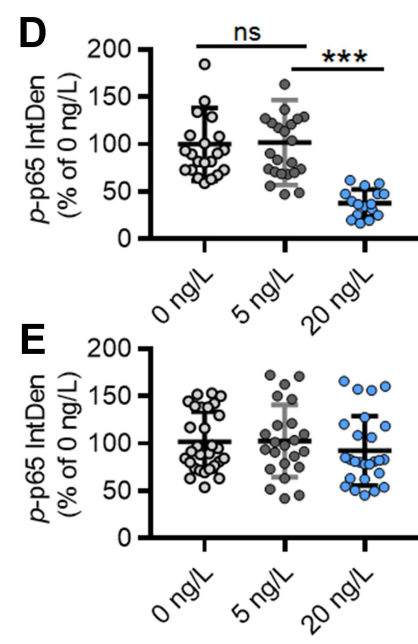

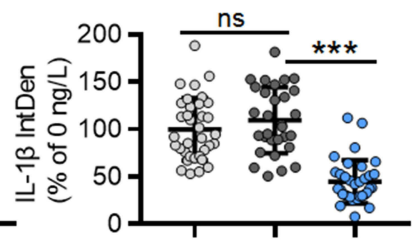

$0^{\text {(ल) }} 5^{(0)} \gamma^{(0)}$

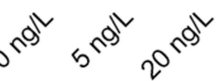

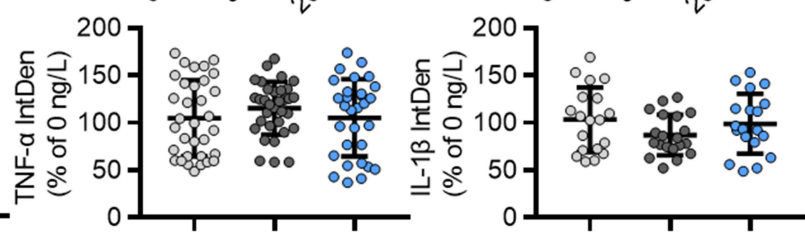

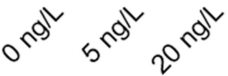
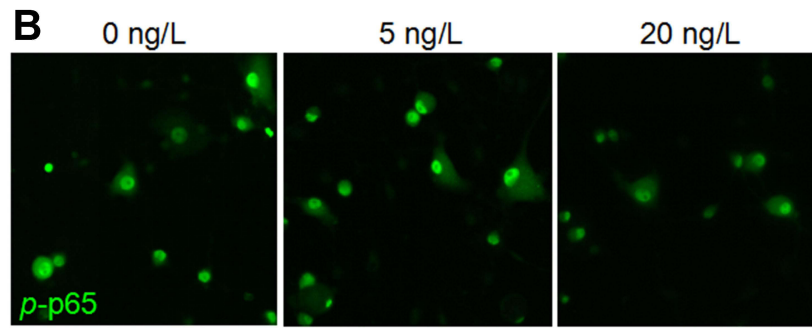

C
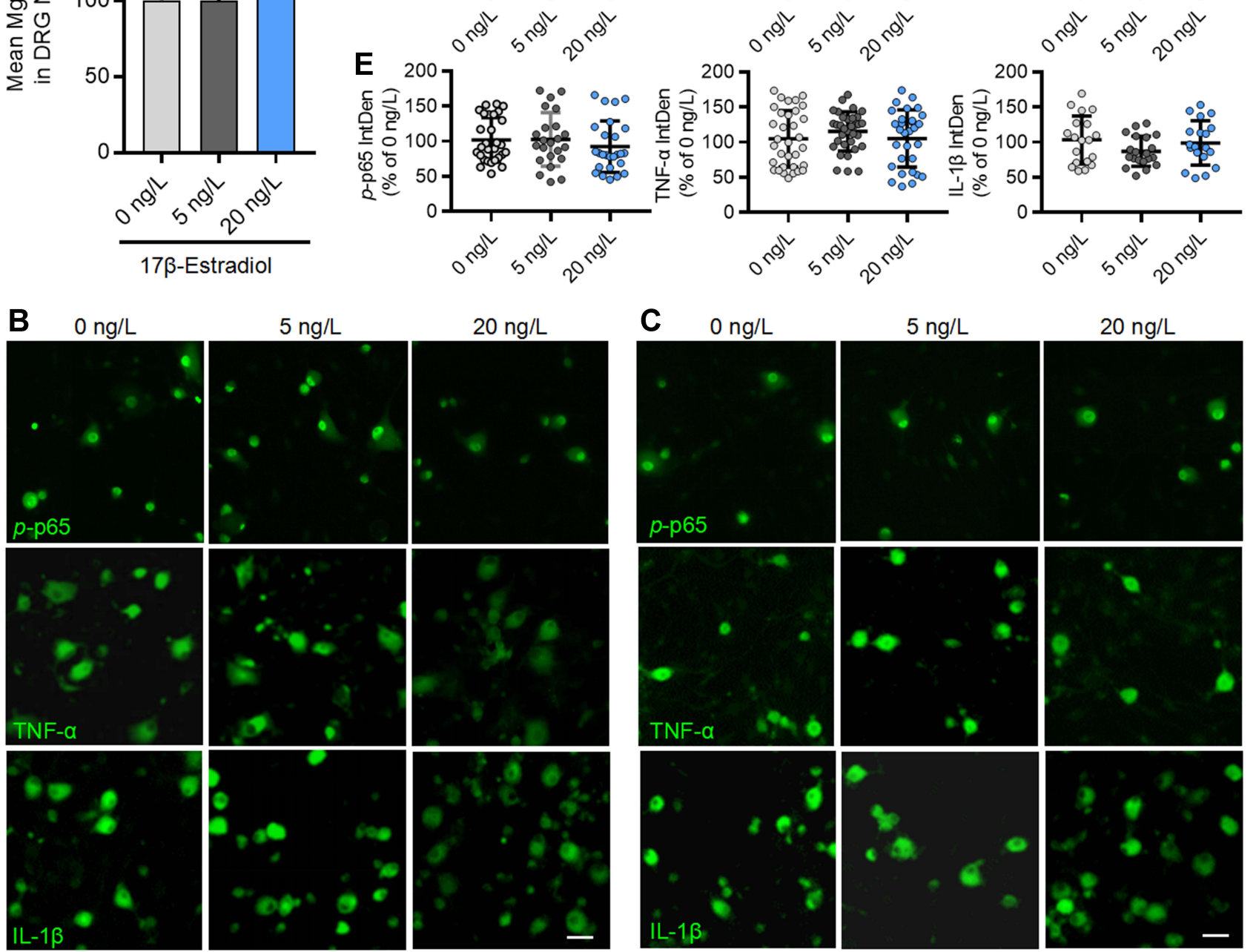

Figure I 2 Estrogen at physiological concentration elevates intracellular $\mathrm{Mg}^{2+}$ and downregulates $p$-p65, TNF- $\alpha$ and IL-I $\beta$ in cultured DRG neurons. (A) Intracellular free $\mathrm{Mg}^{2+}$ in cultured DRG neurons, determined by multifunctional microplate reader, was elevated by $17 \beta$-Estrogen at $10 \mathrm{ng} / \mathrm{L}$ but not by at $5 \mathrm{ng} / \mathrm{L}$ ( $\mathrm{n}=22-24 \mathrm{plate} / \mathrm{group}$ ). (B and C) Representative immunofluorescent staining images show the expressions of $p$-p65, TNF- $\alpha$ and IL-I $\beta$ in DRG neurons cultured in normal medium containing 0.7 mM $\mathrm{Mg}^{2+}(\mathbf{B})$ and in $\mathrm{Mg}^{2+}$ free medium (C) in the presence of different concentrations of $17 \beta$-Estradiol; Scale bar: $20 \mu \mathrm{m}$. (D and E) Statistical analysis of immunofluorescence intensities of $p$-p65, TNF- $\alpha$ and IL-I $\beta$ in DRG neurons cultured in normal medium (D) and $\mathrm{Mg}^{2+}$ free medium (E) with different concentrations of I7 $\beta$-Estradiol ( $\mathrm{n}=4-5$ fields per group; All the neurons in $20 \times$ fields were counted). The data were analyzed by one-way ANOVA with Tukey's test. $* P<0.05$, $* * * P<0.00 \mathrm{I}$, vs 5 ng/L I7 $\beta$-Estradiol. Abbreviation: ns, not significant.

\section{Discussion}

In the present work, we showed for the first time that the chronic pain hypersensitivity, memory decline, depressionlike behaviors were substantially prevented in OVX mice and were attenuated in aged female mice by chronic oral administration of L-TAMS (Figures 2,3). Then, we showed that the neuroinflammation, manifested as upregulation of $p$-p65, TNF- $\alpha$, IL-1 $\beta, p$-IкB $\alpha$, and glial activation in OVX and aged female mice was associated with extracellular and intracellular $\mathrm{Mg}^{2+}$ deficiency. Both of them were significantly attenuated by oral L-TAMS (Figures 47,9-10). Finally, we revealed that estrogen decline induced neuroinflammation by reducing intracellular $\mathrm{Mg}^{2+}$ in cultured DRG neurons (Figures 11 and 12). Together, estrogen decline causes neuroinflammation by reducing intracellular $\mathrm{Mg}^{2+}$, leading to neuronal disorders. Chronic 
oral application of L-TAMS may be a novel approach for treating menopause-related neuronal disorders.

Previous works from different groups have shown that OVX induces neuroinflammation (overproduction of inflammatory cytokines and glial activation in CNS) and/or memory decline, depression-like behaviors in mice, ${ }^{45-53}$ and in rats. $^{54-58}$ Consistently, in the present work we found that chronic pain and memory/emotional deficits were associated with neuroinflammation in OVX and aged female mice. This is in line with clinical data showing that chronic pain is present in $35.0 \%$ of the surveyed population of 1207 subjects, the incidence of chronic pain is much higher in old women. ${ }^{59}$ The incidence of depressive symptom is $32.3 \%$ in perimenopausal and early postmenopausal women. ${ }^{60}$

A recent work shows that OVX does not induce working memory deficits and depression-like behavior in mice. ${ }^{61}$ While in that work, the behavioral changes were assessed around 5 weeks after OVX. In the present work, memory function, depression-like behaviors and neuroinflammation were evaluated 12 and 13 weeks after ovariectomy, respectively (see Figure 1 for experimental procedure). The time, at which the experiments were performed after OVX, may contribute to different results. Consistently, it has been shown that long-term ovariectomy (20 weeks after OVX) but not short-term OVX (6 weeks after OVX) results in a significant decrease on the time spent in the open arms in the elevated plus-maze test compared to control animals ${ }^{62}$ and that 12 weeks after OVX mice began to develop significant cognitive dysfunction. ${ }^{28}$ Thus, the effect of OVX on memory/emotion may be time-dependent.

\section{The Treatment for Menopause-Related Chronic Pain and Memory/Emotional Deficits}

Hormone replace therapy (HRT) with estrogen is used to treat muscular pain, ${ }^{63}$ cognitive impairment ${ }^{39,64}$ and mood depression $^{60,65}$ in menopause women. The HRT has been vigorously debated, since its first use in 1940s. Earlier data show that HRT reduces coronary heart disease and mortality, while the later randomized trials in older women (aged $>60$ years) show it has no such effect (see ${ }^{66}$ for a review). A recent systematic review indicates that long-term HRT increases the risks of thromboembolic disease, breast cancer and endometrial cancer, and is not indicated for prevention of cardiovascular disease, dementia or deterioration of cognitive function in postmenopausal women. ${ }^{67}$ Therefore, the benefit of HRT for menopause symptom might be limited.

Clinical data show that IL-1 and TNF- $\alpha$ in plasma elevate in women with both $\mathrm{OVX}^{68}$ and menopause. ${ }^{69}$ Accumulative experimental evidence has demonstrated that the overproduction of these inflammatory cytokines is necessary and even sufficient to induce chronic pain, memory decline and mood depression in rodents. ${ }^{7,8,70,71}$ It has been proposed that the estrogen decline-induced neuronal disorders are mediated by inflammation. ${ }^{14}$ While how estrogen decline causes inflammation in nervous system remains unclear.

In the present work, we found that both $17 \beta$-estrogen in serum and free $\mathrm{Mg}^{2+}$ in extracellular fluids (serum and CSF) and inside DRG neurons were reduced in OVX and aged mice. Oral L-TAMS improved $\mathrm{Mg}^{2+}$ deficiency but did not affect $17 \beta$-estrogen (Figure 11). Our previous work shows that reducing $\mathrm{Mg}^{2+}$ from $8 \mathrm{mM}$ to $6 \mathrm{mM}$ activates TNF- $\alpha$ NF-KB pathway in cultured rat DRG neurons. ${ }^{10}$ Importantly, we showed that in cultured DRG neurons, $17 \beta$-estrogen at a physiological concentration $(20 / \mathrm{ng} / \mathrm{L}$ as measured in adult mice, Figure 11E) but not at $5 \mathrm{ng} / \mathrm{L}$ increased intracellular $\mathrm{Mg}^{2+}$ and downregulated $p-\mathrm{p} 65$, TNF- $\alpha$ and IL-1 $\beta .17 \beta-$ Estrogen had no anti-inflammation effect in $\mathrm{Mg}^{2+}$ free culture medium (Figure 12). Together, $\mathrm{Mg}^{2+}$ deficiency is critical for estrogen decline-induced upregulation of $p$-p65, TNF- $\alpha$ and IL-1 $\beta$ in DRG neurons. Accordingly, normalization of intracellular $\mathrm{Mg}^{2+}$ may contribute to the antiinflammation effect by $17 \beta$-estrogen. Of course, we cannot rule out that $17 \beta$-estrogen may inhibit the neuroinflammation and neuronal disorders with other mechanisms. Further studies are needed to clarify how estrogen decline leads to intracellular $\mathrm{Mg}^{2+}$ deficiency. Previous works show that $31 \%$ of $\mathrm{Mg}^{2+}$ in the body is distributed inside cells, where it functions as a coactivator for 600 enzymes (see ${ }^{24}$ for a review). Dysfunction of which enzyme(s) leads to neuroinflammation remains elusive.

As supplement $\mathrm{Mg}^{2+}$ by oral L-TAMS substantially prevented or reversed the chronic pain, memory decline, depression-like behaviors and the neuroinflammation in OVX and aged mice. Therefore, supplement $\mathrm{Mg}^{2+}$ may be an alternative or even better treatment for menopause symptom.

\section{The Role of Increased Calcitonin Gene- Related Peptide in Spinal Dorsal Horn in Chronic Pain}

The upregulation of CGRP (a marker for peptidergic $\mathrm{C}$-fiber) in spinal dorsal horn has been demonstrated in 
many animal models of chronic pain, including chemotherapy, ${ }^{10}$ spinal cord injury, ${ }^{72}$ higher frequency noxious stimulation of peripheral nerve. ${ }^{5}$ In the present work, we found that CGRP also increased in spinal dorsal horn in OVX and in aged mice. Importantly, the change is paralleled with synaptic potentiation mediated by C-fibers and chronic pain hypersensitivity. Interestingly, we showed that CGRP was colocalized with $p$-p65, TNF- $\alpha$ and IL-1 $\beta$ in DRG neurons, and oral L-TAMS, which inhibits neuroinflammation, substantially prevented the increase in CGRP. The data indicate that neuroinflammation may play a role for the change. Further studies are needed to clarify the pathological meaning of the change and underlying mechanisms.

\section{The Neuron-Glia Interaction Mediated by Proinflammatory Cytokines May}

\section{Contribute to Persistent} Neuroinflammation

It has been well established that in DRG, activation of satellite glial cells, which closely envelop cell bodies of sensory neurons, contributes to chronic pain by augmenting neuronal activity via releasing bioactive substances, including ATP, glutamate and cytokines, such as TNF- $\alpha$ and IL-1 $\beta$, and fractalkine. ${ }^{73}$ In spinal cord, TNF- $\alpha$ and IL$1 \beta$ released by the activated microglia and astrocytes enhance the synaptic transmission, leading to chronic pain. ${ }^{74}$ That is, the proinflammatory cytokines released from activated glial cells lead to chronic pain. ${ }^{75}$

Accumulating evidence shows that TNF- $\alpha$-NF-KB pathway is activated in the neurons of DRG and dorsal horn in many chronic pain models. TNF- $\alpha$ is upregulated in DRG and spinal dorsal horn neurons in models of L5ventral root transection and partial sciatic nerve transection. ${ }^{40,76}$ With the use of NF-KB reporter mice, it has been shown that activity of NF-KB is increased in neurons of spinal dorsal horn in response to peripheral nerve transection. ${ }^{77}$ The upregulation of NF-KB in DRG neurons is important for both inflammatory pain $^{78}$ and neuropathic pain. ${ }^{79}$ With the use of in situ hybridization, Niu et al show that Tnf- $\alpha$ mRNA is upregulated in the neurons of DRG and spinal dorsal horn after coronary artery occlusion in rats. ${ }^{80}$ Our recent works show that TNF- $\alpha$ and $p$-p65 was upregulated in the neurons of DRG and spinal dorsal horn in vincristine-induced peripheral neuropathy, ${ }^{10}$ and $p$-p65 was also upregulated in DRG neurons in L5 spinal nerve ligation models of neuropathic pain. ${ }^{81}$ In the present work, we showed that $p$-p65, TNF- $\alpha$ and IL- $\beta$ were upregulated in the neurons of DRG, spinal dorsal horn and hippocampus, which is associated with chronic pain and memory/emotional deficits in OVX and aged mice. With in situ hybridization, we showed that Tnf and Il-1 $\beta$ mRNAs were expressed in the neurons of DRGs and spinal dorsal horn of OVX and aged mice. Together, the data indicate that apart from glial cells, the neurons in peripheral and central nervous system are also capable of producing the proinflammatory cytokines, which may initiate or maintain glial activation ${ }^{70,82-85}$ in pathological conditions. The neuron-glia interaction mediated by proinflammatory cytokines may contribute to neuronal disorders by producing persistent neuroinflammation. The inhibition of TNF- $\alpha$-NF-KB pathway in neurons may impede glial activation by interrupting the neuron-glia interaction. This may explain our finding that oral L-TAMS attenuated glial activation in spinal dorsal horn and in hippocampus, while $p$-p65, TNF- $\alpha$ and IL- $1 \beta$ were mainly expressed in neurons and sparsely in glial cells in OVX and aged mice. Further studies are needed to elucidate the mechanisms underlying the proinflammatory cytokines activating glial cells.

\section{The Approaches for Treating the Inflammation-Related Chronic Diseases}

Compelling evidence demonstrates that inflammation plays a key role in many, if not all, chronic diseases. ${ }^{86}$ However, the treatment of the inflammation remains a big challenge in clinical practice. Inflammation has many physiological functions, such as protecting the host from infections by bacteria and viruses, and promoting tissue repair and recovery. ${ }^{87,88}$ In nervous system TNF- $\alpha / \mathrm{NF}-\kappa \mathrm{B}$ signaling is important for memory storage. ${ }^{89}$ Microglia and astrocytes are crucial for regulating neuronal structures and activities ${ }^{90}$ and neurogenesis. ${ }^{91}$ Thus, normal inflammation response is essential. However, excessive inflammation, such as neuroinflammation, ie, persistent overproduction of inflammatory cytokines and glial activation play key roles in neuropathic pain, ${ }^{41}$ Alzheimer's disease $^{42}$ and depression. ${ }^{43,44}$ Therefore, the correct stratagem for treating inflammation-related diseases is to bring it back to normal level. This is difficult to achieve using the agents that inhibit inflammatory cytokine and glial activation. It has been shown that $\mathrm{Mg}^{2+}$ deficiency contributes to many inflammation-related chronic diseases, such as hypertension, ischemic heart disease, stroke, metabolic syndrome, diabetes and colorectal cancer. ${ }^{92}$ Our 
previous works show that antineoplastic agents (vincristine oxaliplatin and cyclophosphamide) induce neuroinflammation, and chronic pain, memory decline and depressionlike behaviors via producing $\mathrm{Mg}^{2+}$ deficiency. ${ }^{10-12}$ In this present work we further showed that $\mathrm{Mg}^{2+}$ deficiency did the same in animal models of menopause. Together, $\mathrm{Mg}^{2+}$ deficiency plays a key role in persistent inflammation and chronic diseases. Accordingly, supplementary $\mathrm{Mg}^{2+}$ can bring the inflammation back to but never below normal level. We used L-TAMS to supplement $\mathrm{Mg}^{2+}$, because a previous work ${ }^{20}$ show that only L-TAMS but not other magnesium compounds $\left(\mathrm{MgCl}_{2}, \mathrm{Mg}\right.$ citrate, $\mathrm{Mg}$ gluconate) is able to elevate $\mathrm{Mg}^{2+}$ in the CSF of rats. Increasing the plasma $\mathrm{Mg}^{2+}$ by three-fold via intravenous infusion of $\mathrm{MgSO}_{4}$ does not elevate $\mathrm{Mg}^{2+}$ in the CSF in human patients. ${ }^{93}$

\section{Conclusion}

The neuroinflammation resulting from $\mathrm{Mg}^{2+}$ deficiency contributes to the chronic pain hypersensitivity, memory and emotional deficits in OVX and aged mice. Supplementary $\mathrm{Mg}^{2+}$ by chronic oral L-TAMS is effective for the attenuation of the neuroinflammation and neuronal disorders induced by estrogen decline.

\section{Abbreviations}

L-TAMS, magnesium-L-threonate; OVX, ovariectomy; $p$-p65, phospho-p65; NF-кB, nuclear factor-kappaB; TNF- $\alpha$, tumor necrosis factor-alpha; IL-1 $\beta$, interleukin-1 beta; DRG, dorsal root ganglion; PWT, paw withdrawal threshold; CPP, conditioned place preference; NORT, novel object recognition test; FST, forced swimming test; TST, tail suspension test; IntDen, integrated density; CSF, cerebrospinal fluid; CGRP, calcitonin gene-related peptide; IB4, isolectin $\mathrm{B}_{4}$; HRT, hormone replace therapy.

\section{Acknowledgments}

This study was supported by the National Natural Science Foundation of China (31771166 to XGL).

\section{Author Contributions}

All authors made a significant contribution to the work reported, whether that is in the conception, study design, execution, acquisition of data, analysis and interpretation, or in all these areas: took part in drafting, revising or critically reviewing the article; gave final approval of the version to be published; have agreed on the journal to which the article has been submitted; and agree to be accountable for all aspects of the work.

\section{Disclosure}

The authors claim that there are no conflicts of interest.

\section{References}

1. Gibson CJ, Li Y, Bertenthal D, et al. Menopause symptoms and chronic pain in a national sample of midlife women veterans. Menopause. 2019;26(7):708-713. doi:10.1097/GME.0000000000001312

2. Lu CB, Liu P-F, Zhou Y-S, et al. Musculoskeletal pain during the menopausal transition: a systematic review and meta-analysis. Neural Plast. 2020;2020:8842110. doi:10.1155/2020/8842110

3. Weber MT, Maki PM, McDermott MP. Cognition and mood in perimenopause: a systematic review and meta-analysis. J Steroid Biochem Mol Biol. 2014;142:90-98. doi:10.1016/j.jsbmb.2013.06. 001

4. Soares CN. Depression and menopause: an update on current knowledge and clinical management for this critical window. Med Clin North Am. 2019;103(4):651-667. doi:10.1016/j.mcna.2019.03.001

5. Zhou LJ, Peng J, Xu Y-N, et al. Microglia are indispensable for synaptic plasticity in the spinal dorsal horn and chronic pain. Cell Rep. 2019;27(13):3844-3859 e6. doi:10.1016/j.celrep.2019.05.087

6. Ren WJ, Liu Y, Zhou L-J, et al. Peripheral nerve injury leads to working memory deficits and dysfunction of the hippocampus by upregulation of TNF-alpha in rodents. Neuropsychopharmacology. 2011;36(5):979-992. doi:10.1038/npp.2010.236

7. Liu Y, Zhou L-J, Wang J, et al. TNF-alpha differentially regulates synaptic plasticity in the hippocampus and spinal cord by microgliadependent mechanisms after peripheral nerve injury. J Neurosci. 2017;37(4):871-881. doi:10.1523/JNEUROSCI.2235-16.2016

8. Mai CL, Wei X, Gui W-S, et al. Differential regulation of GSK-3beta in spinal dorsal horn and in hippocampus mediated by interleukin1 beta contributes to pain hypersensitivity and memory deficits following peripheral nerve injury. Mol Pain. 2019;15:1744806 919826789. doi:10.1177/1744806919826789

9. Mai CL, Tan Z, Xu Y-N, et al. CXCL12-mediated monocyte transmigration into brain perivascular space leads to neuroinflammation and memory deficit in neuropathic pain. Theranostics. 2021;11 (3):1059-1078. doi:10.7150/thno.44364

10. Xu T, Li D, Zhou X, et al. Oral application of Magnesium-1-threonate attenuates vincristine-induced allodynia and hyperalgesia by normalization of tumor necrosis factor- $\alpha /$ nuclear factor- $\kappa \mathrm{B}$ signaling. Anesthesiology. 2017;126(6):1151-1168. doi:10.1097/ALN.0000000 000001601

11. Chen JL, Zhou X, Liu B-L, et al. Normalization of magnesium deficiency attenuated mechanical allodynia, depressive-like behaviors, and memory deficits associated with cyclophosphamideinduced cystitis by inhibiting TNF-alpha/NF-kappaB signaling in female rats. J Neuroinflammation. 2020;17(1):99. doi:10.1186/ s12974-020-01786-5

12. Zhou X, Huang Z, Zhang J, et al. Chronic oral administration of magnesium-L-threonate prevents oxaliplatin-induced memory and emotional deficits by normalization of TNF- $\alpha / N F-\kappa B$ signaling in rats. Neurosci Bull. 2020;37:55-69.

13. Gameiro CM, Romão F, Castelo-Branco C. Menopause and aging: changes in the immune system-a review. Maturitas. 2010;67(4):316320. doi:10.1016/j.maturitas.2010.08.003

14. $\mathrm{Au} \mathrm{A}$, Feher A, McPhee L, et al. Estrogens, inflammation and cognition. Front Neuroendocrinol. 2016;40:87-100. doi:10.1016/j. yfrne.2016.01.002 
15. Reginster JY, Strause L, Deroisy R, et al. Preliminary report of decreased serum magnesium in postmenopausal osteoporosis. Magnesium. 1989;8(2):106-109.

16. Steidl L, Ditmar R. Blood magnesium, calcium and zinc in osteoporosis. Acta Univ Palacki Olomuc Fac Med. 1991;129:91-98.

17. Turner RT, Vandersteenhoven JJ, Bell NH. The effects of ovariectomy and 17 beta-estradiol on cortical bone histomorphometry in growing rats. J Bone Miner Res. 1987;2(2):115-122. doi:10.1002/ jbmr.5650020206

18. Mazur A, Maier JAM, Rock E, et al. Magnesium and the inflammatory response: potential physiopathological implications. Arch Biochem Biophys. 2007;458(1):48-56. doi:10.1016/j. abb.2006.03.031

19. Serefko A, Szopa A, Poleszak E. Magnesium and depression. Magnes Res. 2016;29(3):112-119. doi:10.1684/mrh.2016.0407

20. Slutsky I, Abumaria N, Wu L-J, et al. Enhancement of learning and memory by elevating brain magnesium. Neuron. 2010;65(2):165177. doi:10.1016/j.neuron.2009.12.026

21. Ying YL, Wei X-H, Xu X-B, et al. Over-expression of P2X7 receptors in spinal glial cells contributes to the development of chronic postsurgical pain induced by skin/muscle incision and retraction (SMIR) in rats. Exp Neurol. 2014;261:836-843. doi:10.1016/j. expneurol.2014.09.007

22. Wang J, Liu Y, Zhou L-J, et al. Magnesium L-threonate prevents and restores memory deficits associated with neuropathic pain by inhibition of TNF-alpha. Pain Physician. 2013;16(5):E563-75.

23. Liu G, Weinger JG, Lu Z-L, et al. Efficacy and safety of MMFS-01, a synapse density enhancer, for treating cognitive impairment in older adults: a randomized, double-blind, placebo-controlled trial. $J$ Alzheimers Dis. 2016;49(4):971-990. doi:10.3233/JAD-150538

24. Gile J, Ruan G, Abeykoon J, et al. Magnesium: the overlooked electrolyte in blood cancers? Blood Rev. 2020;44:100676. doi:10.1016/j.blre.2020.100676

25. Sophocleous A, Idris AI. Rodent models of osteoporosis. Bonekey Rep. 2014;3:614. doi:10.1038/bonekey.2014.109

26. Lasota A, Danowska-Klonowska D. Experimental osteoporosis-different methods of ovariectomy in female white rats. Rocz Akad Med Bialymst. 2004;49(Suppl 1):129-131.

27. Li W, Yu J, Liu Y, et al. Elevation of brain magnesium prevents synaptic loss and reverses cognitive deficits in Alzheimer's disease mouse model. Mol Brain. 2014;7:65. doi:10.1186/s13041-0140065-y

28. Zhang S, An X, Huang S, et al. AhR/miR-23a-3p/PKC $\alpha$ axis contributes to memory deficits in ovariectomized and normal aging female mice. Mol Ther Nucleic Acids. 2021;24:79-91. doi:10.1016/ j.omtn.2021.02.015

29. Chaplan SR, Bach FW, Pogrel JW, et al. Quantitative assessment of tactile allodynia in the rat paw. $J$ Neurosci Methods. 1994;53(1):5563. doi:10.1016/0165-0270(94)90144-9

30. King T, Vera-Portocarrero L, Gutierrez T, et al. Unmasking the tonicaversive state in neuropathic pain. Nat Neurosci. 2009;12(11):13641366. doi: $10.1038 / \mathrm{nn} .2407$

31. Ennaceur A, Delacour J. A new one-trial test for neurobiological studies of memory in rats. 1: behavioral data. Behav Brain Res. 1988;31(1):47-59. doi:10.1016/0166-4328(88)90157-X

32. Lalonde R. The neurobiological basis of spontaneous alternation. Neurosci Biobehav Rev. 2002;26(1):91-104. doi:10.1016/S01497634(01)00041-0

33. Porsolt RD, Bertin A, Jalfre M. Behavioral despair in mice: a primary screening test for antidepressants. Arch Int Pharmacodyn Ther. 1977;229(2):327-336.

34. Steru L, Chermat R, Thierry B, et al. The tail suspension test: a new method for screening antidepressants in mice. Psychopharmacology (Berl). 1985;85(3):367-370. doi:10.1007/BF00428203
35. Liu XG, Sandkuhler J. Characterization of long-term potentiation of C-fiber-evoked potentials in spinal dorsal horn of adult rat: essential role of NK1 and NK2 receptors. J Neurophysiol. 1997;78(4):19731982. doi:10.1152/jn.1997.78.4.1973

36. Chen X, Pang R-P, Shen K-F, et al. TNF-alpha enhances the currents of voltage gated sodium channels in uninjured dorsal root ganglion neurons following motor nerve injury. Exp Neurol. 2011;227:279286. doi:10.1016/j.expneurol.2010.11.017

37. Abernethy MH, Fowler RT. Micellar improvement of the calmagite compleximetric measurement of magnesium in plasma. Clin Chem. 1982;28(3):520-522. doi:10.1093/clinchem/28.3.520

38. Szoeke CE, Cicuttini FM, Guthrie JR, et al. The relationship of reports of aches and joint pains to the menopausal transition: a longitudinal study. Climacteric. 2008;11(1):55-62. doi:10.1080/13697130701746006

39. Luine VN. Estradiol and cognitive function: past, present and future. Horm Behav. 2014;66(4):602-618. doi:10.1016/j.yhbeh.2014.08.011

40. Xu JT, Xin W-J, Zang Y, et al. The role of tumor necrosis factor-alpha in the neuropathic pain induced by Lumbar 5 ventral root transection in rat. Pain. 2006;123(3):306-321. doi:10.1016/j.pain.2006.03.011

41. Ellis A, Bennett DL. Neuroinflammation and the generation of neuropathic pain. Br J Anaesth. 2013;111(1):26-37. doi:10.1093/bja/aet128

42. Calsolaro V, Edison P. Neuroinflammation in Alzheimer's disease: current evidence and future directions. Alzheimers Dement. 2016;12 (6):719-732. doi:10.1016/j.jalz.2016.02.010

43. Benedetti F, Aggio V, Pratesi ML, et al. Neuroinflammation in bipolar depression. Front Psychiatry. 2020;11:71. doi:10.3389/ fpsyt.2020.00071

44. Walker AK, Kavelaars A, Heijnen CJ, et al. Neuroinflammation and comorbidity of pain and depression. Pharmacol Rev. 2014;66(1):80 101. doi:10.1124/pr.113.008144

45. Liu T, Ma Y, Zhang R, et al. Resveratrol ameliorates estrogen deficiency-induced depression- and anxiety-like behaviors and hippocampal inflammation in mice. Psychopharmacology (Berl). 2019;236 (4):1385-1399. doi:10.1007/s00213-018-5148-5

46. Xu Y, Sheng H, Bao Q, et al. NLRP3 inflammasome activation mediates estrogen deficiency-induced depression- and anxiety-like behavior and hippocampal inflammation in mice. Brain Behav Immun. 2016;56:175-186. doi:10.1016/j.bbi.2016.02.022

47. Liang J, Wu Y, Yuan H, et al. Dendrobium officinale polysaccharides attenuate learning and memory disabilities via anti-oxidant and antiinflammatory actions. Int J Biol Macromol. 2019;126:414-426. doi:10.1016/j.ijbiomac.2018.12.230

48. Wang Y, Xu Y, Sheng H, et al. Exercise amelioration of depressionlike behavior in OVX mice is associated with suppression of NLRP3 inflammasome activation in hippocampus. Behav Brain Res. 2016;307:18-24. doi:10.1016/j.bbr.2016.03.044

49. Wu SY, Chen Y-W, Tsai S-F, et al. Estrogen ameliorates microglial activation by inhibiting the Kir2.1 inward-rectifier $\mathrm{K}(+)$ channel. $S c i$ Rep. 2016;6:22864. doi:10.1038/srep22864

50. Benedusi V, Meda C, Della Torre S, et al. A lack of ovarian function increases neuroinflammation in aged mice. Endocrinology. 2012;153 (6):2777-2788. doi:10.1210/en.2011-1925

51. Vegeto E, Belcredito S, Ghisletti S, et al. The endogenous estrogen status regulates microglia reactivity in animal models of neuroinflammation. Endocrinology. 2006;147(5):2263-2272. doi:10.1210/ en.2005-1330

52. Khamphukdee C, Monthakantirat O, Chulikhit Y, et al. Antidementia effects of Alternanthera philoxeroides in ovariectomized mice supported by NMR-based metabolomic analysis. Molecules. 2021;26 (9):2789. doi:10.3390/molecules26092789

53. Legorreta-Herrera M, Nava-Castro KE, Palacios-Arreola MI, et al. Sex-associated differential mRNA expression of cytokines and its regulation by sex steroids in different brain regions in a plasmodium berghei ANKA model of cerebral malaria. Mediators Inflamm. 2018;2018:5258797. doi:10.1155/2018/5258797 
54. Ge F, Yang H, Lu W, et al. Ovariectomy induces microglial cell activation and inflammatory response in rat prefrontal cortices to accelerate the chronic unpredictable stress-mediated anxiety and depression. Biomed Res Int. 2020;2020:3609758. doi:10.1155/2020/3609758

55. Wu B, Song Q, Zhang Y, et al. Antidepressant activity of $\omega-3$ polyunsaturated fatty acids in ovariectomized rats: role of neuroinflammation and microglial polarization. Lipids Health Dis. 2020;19 (1):4. doi:10.1186/s12944-020-1185-2

56. Wyse AT, Siebert C, Bobermin LD, et al. Changes in inflammatory response, redox status and $\mathrm{Na}(+), \mathrm{K}(+)$-ATPase activity in primary astrocyte cultures from female Wistar rats subject to ovariectomy. Neurotox Res. 2020;37(2):445-454. doi:10.1007/s12640-01900128-5

57. Xu Y, Sheng H, Tang Z, et al. Inflammation and increased IDO in hippocampus contribute to depression-like behavior induced by estrogen deficiency. Behav Brain Res. 2015;288:71-78. doi:10.1016/j. bbr.2015.04.017

58. Kireev RA, Vara E, Viña J, et al. Melatonin and oestrogen treatments were able to improve neuroinflammation and apoptotic processes in dentate gyrus of old ovariectomized female rats. Age (Dordr). 2014;36(5):9707. doi:10.1007/s11357-014-9707-3

59. Toth $\mathrm{C}$, Lander J, Wiebe S. The prevalence and impact of chronic pain with neuropathic pain symptoms in the general population. Pain Med. 2009;10(5):918-929. doi:10.1111/j.1526-4637.2009.00 655.x

60. Gordon JL, Rubinow DR, Eisenlohr-Moul TA, et al. Efficacy of transdermal estradiol and micronized progesterone in the prevention of depressive symptoms in the menopause transition: a randomized clinical trial. JAMA Psychiatry. 2018;75(2):149-157. doi:10.1001/ jamapsychiatry.2017.3998

61. Pavlock S, McCarthy DM, Kesarwani A, et al. Hippocampal neuroinflammation following combined exposure to cyclophosphamide and naproxen in ovariectomized mice. Int $J$ Neurosci. 2021;1-10. doi:10.1080/00207454.2021.1896508

62. Lagunas N, Calmarza-Font I, Diz-Chaves Y, et al. Long-term ovariectomy enhances anxiety and depressive-like behaviors in mice submitted to chronic unpredictable stress. Horm Behav. 2010;58 (5):786-791. doi:10.1016/j.yhbeh.2010.07.014

63. Watt FE. Musculoskeletal pain and menopause. Post Reprod Health. 2018;24(1):34 43. doi:10.1177/2053369118757537

64. Herrera AY, Hodis HN, Mack WJ, et al. Estradiol therapy after menopause mitigates effects of stress on cortisol and working memory. J Clin Endocrinol Metab. 2017;102(12):4457-4466. doi:10. 1210/jc.2017-00825

65. Schmidt PJ, Ben Dor R, Martinez PE, et al. Effects of estradiol withdrawal on mood in women with past perimenopausal depression: a randomized clinical trial. JAMA Psychiatry. 2015;72(7):714-726. doi:10.1001/jamapsychiatry.2015.0111

66. Lobo RA. Hormone-replacement therapy: current thinking. Nat Rev Endocrinol. 2017;13(4):220-231. doi:10.1038/nrendo.2016. 164

67. Marjoribanks J, Farquhar C, Roberts H, et al. Long-term hormone therapy for perimenopausal and postmenopausal women. Cochrane Database Syst Rev. 2017;1(1):Cd004143. doi:10.1002/14651858. CD004143.pub5

68. Pacifici R, Brown C, Puscheck E, et al. Effect of surgical menopause and estrogen replacement on cytokine release from human blood mononuclear cells. Proc Natl Acad Sci U S A. 1991;88(12):51345138. doi:10.1073/pnas.88.12.5134

69. Pfeilschifter J, Köditz R, Pfohl M, et al. Changes in proinflammatory cytokine activity after menopause. Endocr Rev. 2002;23(1):90-119. doi:10.1210/edrv.23.1.0456

70. Gui WS, Wei X, Mai C-L, et al. Interleukin-1beta overproduction is a common cause for neuropathic pain, memory deficit, and depression following peripheral nerve injury in rodents. Mol Pain. 2016;12:174480691664678. doi:10.1177/1744806916646784
71. Bakare AO, Owoyele BV. Bromelain reduced pro-inflammatory mediators as a common pathway that mediate antinociceptive and antianxiety effects in sciatic nerve ligated Wistar rats. Sci Rep. 2021;11 (1):289. doi:10.1038/s41598-020-79421-9

72. Hou S, Duale H, Rabchevsky AG. Intraspinal sprouting of unmyelinated pelvic afferents after complete spinal cord injury is correlated with autonomic dysreflexia induced by visceral pain. Neuroscience. 2009;159(1):369-379. doi:10.1016/j.neuroscience.2008.12.022

73. Hanani M, Spray DC. Emerging importance of satellite glia in nervous system function and dysfunction. Nat Rev Neurosci. 2020;21 (9):485-498. doi:10.1038/s41583-020-0333-z

74. Grace PM, Hutchinson MR, Maier SF, et al. Pathological pain and the neuroimmune interface. Nat Rev Immunol. 2014;14(4):217-231. doi:10.1038/nri3621

75. Donnelly CR, Andriessen AS, Chen G, et al. Central nervous system targets: glial cell mechanisms in chronic pain. Neurotherapeutics. 2020;17(3):846-860. doi:10.1007/s13311-020-00905-7

76. Yang $\mathrm{CP}$, Cherng $\mathrm{C}-\mathrm{H}, \mathrm{Wu} \mathrm{C}-\mathrm{T}$, et al. Intrathecal ultra-low dose naloxone enhances the antihyperalgesic effects of morphine and attenuates tumor necrosis factor- $\alpha$ and tumor necrosis factor- $\alpha$ receptor 1 expression in the dorsal horn of rats with partial sciatic nerve transection. Anesth Analg. 2013;117(6):1493-1502. doi:10.1213/ ANE.0000000000000020

77. Pollock G, Pennypacker KR, Mémet S, et al. Activation of NFkappaB in the mouse spinal cord following sciatic nerve transection. Exp Brain Res. 2005;165(4):470-477. doi:10.1007/s00221-0052318-6

78. Möser CV, Kynast $\mathrm{K}$, Baatz $\mathrm{K}$, et al. The protein kinase IKKع is a potential target for the treatment of inflammatory hyperalgesia. $J$ Immunol. 2011;187(5):2617-2625. doi:10.4049/jimmunol.100 4088

79. Kanngiesser M, Häussler A, Myrczek T, et al. Inhibitor kappa B kinase beta dependent cytokine upregulation in nociceptive neurons contributes to nociceptive hypersensitivity after sciatic nerve injury. $J$ Pain. 2012;13(5):485-497. doi:10.1016/j.jpain.2012.02.010

80. Niu YL, Guo Z, Zhou RH. Up-regulation of TNF-alpha in neurons of dorsal root ganglia and spinal cord during coronary artery occlusion in rats. Cytokine. 2009;47(1):23-29. doi:10.1016/j.cyto.2009.04.003

81. Xie MX, Zhang X-L, Xu J, et al. Nuclear factor-kappaB Gates Nav1.7 channels in DRG neurons via protein-protein interaction. iScience. 2019;19:623-633. doi:10.1016/j.isci.2019.08.017

82. Gruber-Schoffnegger D, Drdla-Schutting R, Honigsperger C, et al. Induction of thermal hyperalgesia and synaptic long-term potentiation in the spinal cord lamina I by TNF- $\alpha$ and IL-1 $\beta$ is mediated by glial cells. $J$ Neurosci. 2013;33(15):6540-6551. doi:10.1523/ JNEUROSCI.5087-12.2013

83. Brás JP, Bravo J, Freitas J, et al. TNF-alpha-induced microglia activation requires miR-342: impact on NF-kB signaling and neurotoxicity. Cell Death Dis. 2020;11(6):415. doi:10.1038/s41419-0202626-6

84. Basu A, Krady JK, Levison SW. Interleukin-1: a master regulator of neuroinflammation. J Neurosci Res. 2004;78(2):151-156. doi:10. 1002/jnr.20266

85. Kaushik DK, Thounaojam MC, Kumawat KL, et al. Interleukin-1 $\beta$ orchestrates underlying inflammatory responses in microglia via Krüppel-like factor 4. J Neurochem. 2013;127(2):233-244. doi:10. 1111/jnc. 12382

86. Furman D, Campisi J, Verdin E, et al. Chronic inflammation in the etiology of disease across the life span. Nat Med. 2019;25(12):18221832. doi:10.1038/s41591-019-0675-0

87. Netea MG, Balkwill F, Chonchol M, et al. A guiding map for inflammation. Nat Immunol. 2017;18(8):826-831. doi:10.1038/ ni.3790

88. Kotas ME, Medzhitov R. Homeostasis, inflammation, and disease susceptibility. Cell. 2015;160(5):816-827. doi:10.1016/j.cell.2015. 02.010 
89. Meffert MK, Baltimore D. Physiological functions for brain NFkappaB. Trends Neurosci. 2005;28(1):37-43. doi:10.1016/j.tins.20 04.11 .002

90. Kato D, Eto K, Nabekura J, et al. Activity-dependent functions of non-electrical glial cells. J Biochem. 2018;163(6):457-464. doi:10. 1093/jb/mvy023

91. Falk S, Götz M. Glial control of neurogenesis. Curr Opin Neurobiol. 2017;47:188-195. doi:10.1016/j.conb.2017.10.025
92. Nielsen FH. Dietary magnesium and chronic disease. $A d v$ Chronic Kidney Dis. 2018;25(3):230-235. doi:10.1053/j.ackd.20 17.11.005

93. McKee JA, Brewer RP, Macy GE, et al. Magnesium neuroprotection is limited in humans with acute brain injury. Neurocrit Care. 2005;2 (3):342-351. doi:10.1385/NCC:2:3:342

\section{Publish your work in this journal}

The Journal of Inflammation Research is an international, peerreviewed open-access journal that welcomes laboratory and clinical findings on the molecular basis, cell biology and pharmacology of inflammation including original research, reviews, symposium reports, hypothesis formation and commentaries on: acute/chronic inflammation; mediators of inflammation; cellular processes; molecular mechanisms; pharmacology and novel anti-inflammatory drugs; clinical conditions involving inflammation. The manuscript management system is completely online and includes a very quick and fair peerreview system. Visit http://www.dovepress.com/testimonials.php to read real quotes from published authors. 